\title{
Analysis of Factors Affecting to The Competitiveness of The Logistics Enterprises in Mekong Delta, Vietnam under The Integration of Descriptive Statistics and Fuzzy-ISM Approach.
}

\author{
Nguyen Thang Loi ${ }^{1,2}$, N.D.Khoi ${ }^{2}$, H.T.T Hoa ${ }^{3}$, L.K.Chi ${ }^{2}$, H.V.Bay ${ }^{2}$, P.D.T.Anh ${ }^{2}$, Q. L. Da ${ }^{2}$ \\ ${ }^{1}$ Ho Chi Minh City University of Transport, Vietnam. \\ ${ }^{2}$ FPT University, School of Business, Vietnam. \\ ${ }^{3}$ International University, Viet Nam National University Ho Chi Minh City, Vietnam.
}

Loint15@fe.edu.vn, KhoiND4@fe.edu.vn, Htthoa@hcmiu.edu.vn, ChiLKCS130334@fpt.edu.vn, BayHV@fe.edu.vn, Anhpdt@fe.edu.vn, Daql@fe.edu.vn.

Received: June 14, 2021. Received: November 3, 2021. Accepted: November 15, 2021. Published: December 6, 2021.

\begin{abstract}
This paper analyzes the influence of the factors belonging to the Logistics Performance Index (LPI) on the competitiveness of Logistics Enterprises (LEs) in the Mekong Delta (MD), Vietnam. The input factors will be selected from a rigorous document review process combined with an in-depth survey of leading experts in the logistics field. Since then, an integrated approach including Improved Descriptive Statistics (IDS) combined with Fuzzy Interpretive Structure Modeling (FISM) has been structured to achieve this purpose. Specifically, the factors that have the closest relationship with competitiveness will be determined from the results of an improved descriptive statistical method, then the results will be developed using the FISM method under trapezoidal fuzzy number format to realize the importance of factors contributing to improving the competitiveness of logistics companies. The results have shown the impact of 16 sub-factors, which belong in the 4 main factors of Reputation (REP); Timeliness (TIM); Customs (CUS); and Ease of arranging shipments (EAS), on the competitiveness of logistics enterprises in the region analyzed in 4 clusters (Dependency, Association, Autonomy and independence). In which, 6 out of 16 factors have a significant impact on competitiveness that logistics enterprises need to pay more attention to in their operations. These factors will be ranked as REP4, REP 5, REP3, REP1, REP2, EAS1, respectively.
\end{abstract}

Keywords: Descriptive Statistics, Fuzzy-ISM, The Competitiveness, Third-party logistics service providers, Trapezoidal linguistic.

\section{INTRODUCTION}

As the evolvement of the global market with technological progress, especially the market expanding in emerging and small economies, managers regard logistics as a tool to link sectors of corporate strategy. The effective development of logistics services will help increase the competitiveness of the national economy. Currently, the competition among countries is globally getting tougher, which made logistics services becoming one of the country's competitive advantages. Many nations that are well associated to the worldwide system of logistics services can approach many markets and consumers across the globe. Resulting from the development of logistics services is enormous benefits to the economy. Understanding this issue, the Government has proposed policies to stimulate logistics activities to maintain the supply chain of goods and supply the demand for goods circulation and consider this a central element in the economic development strategy. Particularly, the MD region receives the most attention (VCCI, 2020) [1] .

$\mathrm{MD}$, which is the rich natural conditions' region, has become the largest producer of food, aquatic products, and tropical fruit trees in the country. Due to the potential in the output of agricultural and aquatic products, the demand for domestic and export goods transportation is very large in this region. Therefore, the logistics system plays a vital role in the export of regional commodities. Every year, the demand for transporting export goods of the MD is up to tens of millions of tons. However, the agricultural and aquatic products in this region are being restrained by many factors, including the burden of logistics costs. The proof is that $70 \%$ of exported goods must be moved to ports in Ho Chi Minh City and Cai Mep Thi Vai ports' cluster for preservation and storage in warehouses, making the transport service costs of enterprises more bearable from $10-40 \%$ depending on the route and the means of transport used according to the topography of the region in every shipment (Ty, 2019) [2]. Besides transportation costs, the costs that consisted of storage costs, loading costs, and other costs, will be accumulated together to form a total cost block which called by the logistics cost (LC). The LC in the MD is high which caused a burden for businesses. The main reason is agreed that there are many intermediate stages in the process of transporting goods in this region. Even though there are large number of ports and wharves in MD but their characteristics are small size, short, scattered, lacks key logistics centers and satellite systems, lacks empty container yards, warehouse systems at ports. Moreover, lacks food hygiene, safety inspection unit, and qualified irradiation have caused difficulties for transportation as well as increasing logistics costs for businesses in the MD (Reported by Ministry of Industry and Trade of Vietnam, 2021) [3]. This situation shows that reducing logistics costs, improving competitiveness, and developing logistics services in the region to promote export and economic development is a very urgent requirement.

There are many studies on the MD, but the studies are 
problem-specific such as the study of "Impact of Decisions in Freight Transport Management on Rice Logistics in the MD of Vietnam", offering solutions on transport infrastructure thereby progressing rice logistics in Vietnam by Binh and Huong (2020) [4]. Besides, Le and Le (2020) study the factors affecting the decision to outsource logistics services of seafood exporters in the MD. Based on the logistics situation in the MD, lack of synchronous planning and weak logistics lead to an increase in costs in all stages of the production value of agricultural products in the region, reducing the competitiveness of enterprises and the economy of the region [5]. However, these two studies above mainly discussing about logistics in the MD, but they have not fully focused on improving the competitiveness of the logistics industry in this region. Therefore, when realizing the extremely urgent situation, this essay will be studied the factors affecting competitiveness based on Logistics Performance Index (LPI) indicators and offer solutions to improve competitiveness for businesses in the logistics industry in the MD to match the potential that the region brings. Besides using LPI to study the factors affecting the logistics competitiveness of Vietnam as well as in the MD, reputation will be a new factor which has few studies mentioned to be included to analyze whether reputation has an impact on the competitiveness of logistics service enterprises in the MD. Reputation represents the level of prestige and image of a business, increases trust, helps build long-term business relationships and cooperation.

\section{LITERATURE REVIEW}

\section{A. Logistics Performance Index (LPI)}

The Performance Logistics Index (LPI) is an index launched by the World Bank to help countries identify the challenges and opportunities they face in their performance on trade logistics and what they can do to improve their performance. The dataset from the survey of World Bank (2010) allows one to compare and evaluate the logistics development of 160 countries around the world, providing an overview of the current situation as well as the opportunities and challenges that logistics activities are facing [6]. The World Bank (2010) has based on LPI, which is calculated by the weighted average of the country scores on six key dimensions, to assess the logistics capacity of a country as follows:

- Infrastructure (INF) includes infrastructure associated to trade and transport quality.

- Shipments International (EAS) shows how easy it is to arrange for shipments at competitive prices.

- Quality of Logistics Service (QLS) is the capacity and quality of logistics services (Example: Transport operators, customs brokers).

- Tracking and Tracing (TRA) are the ability to track and locate shipments.

- Timeliness (TIM) refers to the punctuality of shipments to their destination.

- Customs (CUS) are the efficiency of the customs clearance process, such as the speed, simplicity, and predictability of customs procedures.

The LPI is created by the results of a worldwide survey of stakeholders on the ground providing feedback on the logistics "friendliness" of the countries in which they have in- depth knowledge and other countries where they trade and have experience of global logistics environment.

LPI results have been not only used in many policy reports and documents for the logistics industry and for logistics users but also been embraced by the academic community. [6]

\section{B. Relevant Theoretical Framework:}

Previously, through international and domestic articles discussing the competitiveness of the logistics industry in Vietnam and other countries, the analysis of factors affecting competitiveness through the LPI is widely applied by Vietnamese and international researchers. Those studies and relevant conceptual frameworks have supported us to refer and identified some gaps to achieve this research. Hereabouts are the research models that we have adopted to make our study more inclusive.

Hanh (2020) has used qualitative methods to elucidate the theoretical basis of competitiveness and identify indicators to measure competitiveness of Vietnam's logistics services industry [7]. In addition, a quantitative method to ascertain the status of the logistics service industry in Vietnam from 2007 to 2018 and find out the factors affecting the competitiveness of the logistics service industry. World Bank (2018) used the results of both recent theoretical and empirical research and on the practical experience of logistics experts to analyze the international LPI's components. Internationally, there are 6 groups of factors affecting competitiveness, including: CUS, INF, EAS, QLS, TRA and TIM. These are all significant components of logistics competitiveness and are frequently adopted by authors in their study. We also applied all six elements in this research with the aspiration to better comprehend what makes the MD Logistics more competitive? As stated by the author, those six factors can positively influence logistics performance and competitiveness. Besides there are also more studies on Logistics competitive advantage from other authors around the world, using the LPI research model. Hamed (2019) resulted that logistics performance and its effects are one of the issues that attract a lot of attention from countries around the world [8]. Accordingly, this article was written by the author with the aim of mentioning and analyzing the performance of the logistics sector in Jordan through the use of a 6 -factor model of the LPI including " (1) Efficiency and effectiveness of processes by customs and border agencies at the borders. (2) Quality of transport-related and IT infrastructure. (3) Ease and affordability of handling shipments in and outside the country. (4) Competence in the local logistics services industry. (5) Ability to track and trace shipments throughout the logistics chain. (6) Timeliness of shipments in reaching the final destination". Limcharoen et al. (2017) have also relied on data from The World Bank's LPI to study Thailand's logistics results over the years "2007, 2010, 2012, 2014 and 2016" and since then provide comments and solutions to this problem [9]. There are 6 factors to evaluate logistics performance that the authors mentioned in the article including "customs, infrastructure, international shipments, logistics quality and competence, tracking and tracing and timeliness". This reveal that Thai Logistics need to pay more attention on three factors "infrastructure, logistics quality and competence, tracking and tracing" to emulate or cooperate with foreign countries. 
Çemberci et al. (2015) caried out research to better comprehend the moderator effect of global competitiveness index on six dimensions of LPI, and the outcomes show that the moderating impact on three including "Competence of arranging competitively priced shipments", "Tracing \& Tracking", "Timeliness" out of six LPI factors [10].

Although there have been many studies on logistics competitiveness in Vietnam and the world. However, not numerous research has been conducted to evaluate the factors affecting the logistics competitiveness of the significant economic region of the MD. And whether these elements can have an impact on the MD logistics, still a question to answer. Notably, this research will be focusing on the logistics competitiveness of the agricultural economic region with commodities such as rice, aquatic products, fruits, etc. From here, provide resolutions to develop the competitiveness of logistics aiming at reduced logistics costs, infrastructure upgrades. And raise the level of logistics commensurate with the scale of the regional economy.

Besides, this research is based not only on the above six evaluation factors of logistics performance but also on another aspect when practicing business culture in Vietnam or in the MD area, which is called "Reputation". In fact, Tian et al. (2008) found that a Third-party logistics provider's reputation is one of the crucial determinants of clients' level of trust in third-party logistics providers [11]. "Since reputation is a source of competitive advantage" stated by Eidat et al. (2008) [12]. Hence, the "Reputation" is appropriate and deserves to be considered for inclusion in the MD competitiveness study. Also, through the survey that we conducted with experts who are managers and business owners about the most important criteria that businesses often use to evaluate and choose logistics service providers. And it resulted as numerous businesses tend to choose a logistics service provider based on the service provider's reputation such as Are they prestigious brands? Are there many branches in different regions? Their Corporate culture including human factors, customer experience, and the long-term relationship. It can be seen that the question is, "Does the factor of reputation have an impact on logistics competitiveness in the MD region?".

Two above models are mentioned which will be applied to refer factors that may affect LEs' competitiveness. From there, we focus the relevant factors to implement to the research model to recognize what factors have influence on MD Logistics competitiveness. The proposed research model will be shown in Figure 1.

With the inheritance of outcomes from some previous studies correlated to research on logistics competitiveness, our thesis will be suggested the following hypotheses:

H1: "Reputation", which is considered as a significant element in how a business and its services are valued, has a positive impact, in the same direction as the competitiveness of the MD Logistics (expectation + ).

$\mathrm{H} 2$ : "Customs", determines that "the efficiency of customs and border management clearance", has a positive impact, in the same direction as the competitiveness of the MD Logistics (expectation + ).

H3: "Infrastructure", is "the quality of trade and transport infrastructure", which has a positive impact, in the same direction as the competitiveness of the MD Logistics $($ expectation +$)$.

H4: "Ease of arranging shipments", which is "the ease of arranging competitively priced shipments", has a positive influence, in the same direction as the competitiveness of the MD Logistics (expectation +).

H5: "Quality of Logistics services", which is described as "the competence and quality of logistics services - trucking, forwarding, and customs brokerage", has a positive impact, in the same direction as the competitiveness of the MD Logistics $($ expectation +$)$.

H6: "Tracking \& Tracing", can be considered as "the ability to track and trace consignments", has a positive impact, in the same direction as the competitiveness of the MD Logistics (expectation + ).

H7: "Timeliness", which can be understood as "the frequency with which shipments reach consignees within scheduled or expected delivery times", has a positive impact, in the same direction as the competitiveness of the MD Logistics (expectation + ).

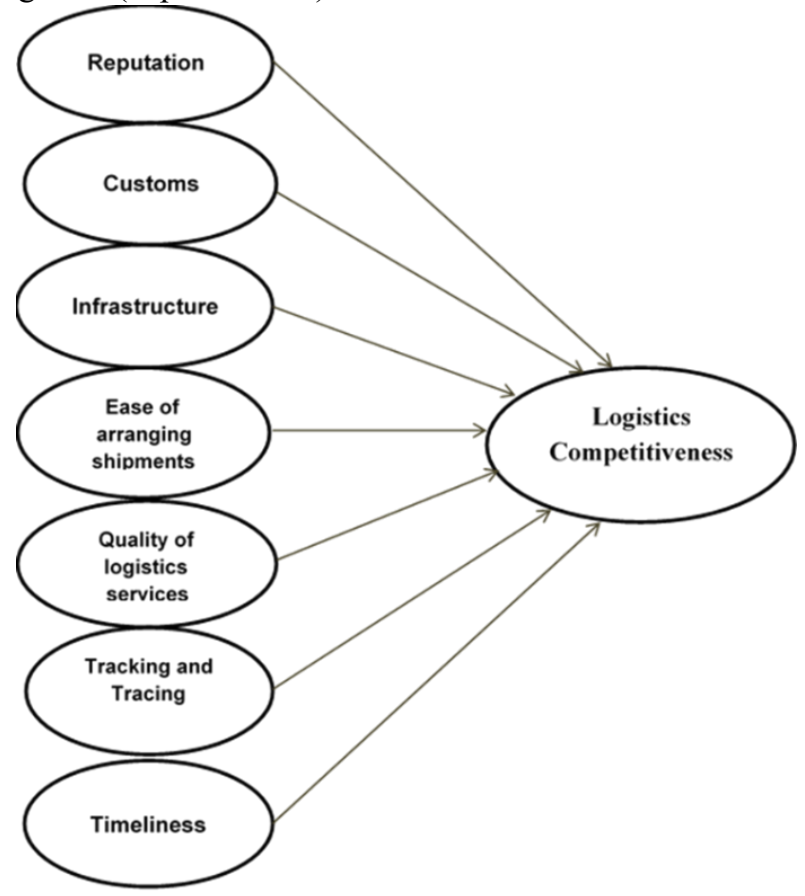

Source: By Authors

Figure 1. The proposed research model

The main contributions of this research are explained as follows:

- Currently, logistics studies in MD, Vietnam have so far not focused on studying the factors affecting the competitiveness of logistics enterprises in an integrated approach from many different perspectives. . In this article, we analyze more deeply about LEs' competition represented by LPI to improve the competitiveness of LEs. In addition, the factors that we research are gathered and considered in the same context from many studies that have been carried out up to the present time and the contributions of leading logistics experts in Vietnam.

- In addition, factors effecting the LEs' competitiveness has been analyzed by a new approach, which has not been found in the previous studies for competitiveness, especially the MD's LEs. The approach considered is the 
integration between IDS and FISM methods under Trapezoidal fuzzy numbers (TFN). This is the next main contribution of this paper. Since, the research objectives are addressed:

$+\quad$ To develop the results of IDS method becoming a input-oriented data of the FISM method, which helps to identify factors that have a close relationship with the competitiveness of The Logistics Enterprises by the literature reviews and the discussion with experts/managers and academicians.

+ To identify the best driving factors which significantly affected the LEs' competitiveness from 16 enablers which are determined by the previous steps.

+ Finally, the conclusion of this paper will be an important input which help the LEs' managers understanding the key performances of their own enterprises' competitiveness. From there, they can make more appropriate decisions dealing with their survive in the present and their strategic plan in the future. This is also a contribution of this article to business management.

\section{METHODOLOGY}

- This paper develops a new integrated IDS-FISM approach for modeling and ranking the important level of the factors effecting the LEs' competitiveness. The integrated IDS-FISM method will help improve the subjectivity of input data when using only the FISM method, by supplementing the primary data source database from the business survey process. businesses and managers at enterprises and customers using logistics services. This data result will be matched with the data source obtained from in-depth interviews with leading logistics experts in the format of FISM method. In this approach, 16 independent sub-variables will be determined by the combination of the literature review, IDS method, managers and experts' ideas. Then, these 16 sub-variables have become the input of the ISM method considered under fuzzy values, which is noted by FISM. The main purpose of FISM is to level the specific importance and determine the relationship between these sub-variables. In addition, to enrich the effecting level of sub-variables, FMIMAC method will be additionally implemented. Since, the sub-variables are not only leveled by FISM method but also divided to 4-cluster through FMICMAC method which consisted Autonomous variables (Cluster I); Dependence variables (II); Linkage variables (III); and Driving variables (IV). All the fuzzy linguistic formats that are used in this paper, are the Trapezoidal Fuzzy (TF) Savitha and George (2017) [13]. The research's framework has been shown in Figure 2. 


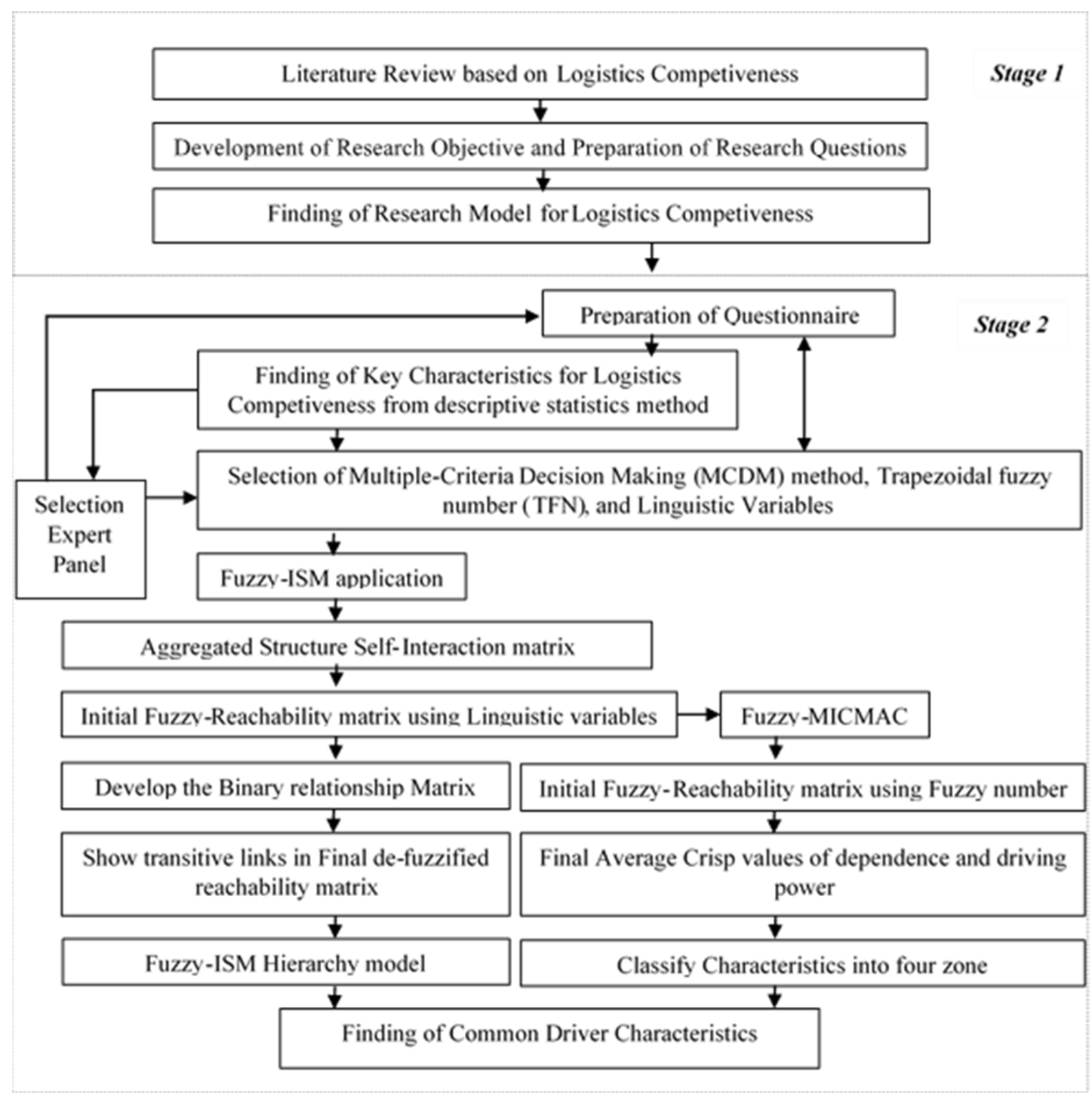

Figure 2. The Study framework

According to Figure 2, both quantitative and qualitative methods are integrated to find out the results via two-stage approaches. In stage I, quantitative methods is mostly used to find out the research model and the related sub-factors as well. Meanwhile, the integration of quantitative and qualitative methods which are represented by IDS, FISM and FMICMAC under the deep interviews that implemented by the LEs' managers and the logistics experts.

Characteristics of LEs' competitiveness were the results of the literature reviews process for LEs' Competitiveness that are focused on the published articles from year 2000 to 2020 and combining with Experts' ideas following the Delphi technique. Since, the seven independent factors including Reputation from Tian et al. (2008) and LPI model contains 6 components respectively CUS, INF, EAS, QLS, TRA and TIM from Hanh (2020) are built $[11,7]$. Key components of the Delphi technique include the communication process, an essential group of experts and feedback Dube and Gawande (2016a) [14]. Besides, the scale of the dependent variable will be based on Peter et al. (1988) [15].

After determining the research model from the Delphi method and the document review process, the elements will be designed into a survey to provide input for the IDS method will be applied in this study.
For IDS step, data will be gathered by both primary and secondary sources. Secondary sources in this step are provided from LEs, Experts, published reports, articles and internet. Meanwhile, primary resources are made by the collection of questionnaire surveys, telephone interviews and personal visits.

The main survey respondents in this step will be companies and professionals with the sample size applied according to Tabachnick and Fidell (1996), when utilizing multivariate statistics, the formula $n=50+8 * m$ is used to compute the minimal sample size to be obtained (m: number of independent variables) [16]. As a result, while determining the number of samples, the above formulas must be met, and the general rule is that it is preferable to have an excess of samples than a shortage of samples. Based on that argument, the study would be more relevant if there were 106 or more samples. In order to make the results of this study as accurate as possible, we will collect at least 120 samples for the enterprises and the experts in the MD. Then an IDS method will be applied to result the sub-factors belonging these 7 main group factors. These factors are further analyzed according to the FISM method. Since the IDS methodology already includes the integration of expert opinion to guide the input of the FISM method, the data collection process for FISM will not be 
necessary. Therefore, the factors relationships that created by the correlation analysis from the IDS method will be considered to replace the data collection process in the format of the ISM.

FISM method in this research is an extended fuzzy format of ISM (Nguyen et al., 2021) [17]. In this paper, the FISM is used in the integration with FMICMAC to form a consolidation method or FISM-FMICMAC method, whose steps are described by Yadav and Singh (2020) [18]

The theory of first fuzzy set was created by Zadeh (1965) to solve the uncertainly problems which are caused by imprecision or vagueness. A fuzzy set $A$ in a universe of discourse $X$ is defined as the set of pairs, $A=$ $\left\{\left(x, \mu_{A}(x)\right): x \in X\right\}$, where $\mu_{A}(x): X \rightarrow[0,1]$ is called the membership value of $x \in X$ in the fuzzy set $A$ [19].

The fuzzy logic is applied in many different fields, of which the most popular is the technology field. Abdullah (2021) developed applications about fuzzy, namely Sugeno-FuzzyLogic to design of high-sensitive fuzzy Proportional-IntegralDerivative controller by means of Matlab and ProgrammableLogic-Controllers for an adjusted of the Development of the Maximum-Power-Point-Tracking scheme [20]. Voloşencu $(2021 \mathrm{a}, \mathrm{b})$ have designed the fuzzy control system to conduct a comparative analysis of the state feedback fuzzy control with the linear control for angular positioning of mechanical parts in which there are few differences in performance criteria between the control methods. In this paper, the authors add to the applied literature of fuzzy logic in the analysis of logistics operation, and the fuzzy format that the authors integrated in the analytical model, is Trapezoidal fuzzy [2122].

According to Nguyen et al. (2021), A Trapezoidal fuzzy number (TFN) denoted by $A$ is defined as $(l, m, n, u)$ where the membership function is given by function (1) [17].

$$
\mu_{A}(x)=\left\{\begin{array}{cl}
0, & x \leq l \\
\frac{x-l}{m-l}, & l \leq x \leq m \\
1, & m \leq x \leq n \\
\frac{u-x}{u-n}, & n \leq x \leq u \\
0, & x \geq u
\end{array} .\right.
$$

\section{DISCUSSIONS AND RESULTS}

\section{A. Descriptive statistics method}

Descriptive statistics methods are used to describe the basic features of the data in a study. They provide simple summaries about the sample and the measures. Together with simple graphics analysis, they form the basis of virtually every quantitative analysis of data [23]. Even when a data analysis draws its main conclusions using inferential statistics, descriptive statistics are generally also presented.[24]. In this paper, we uses The Improved Descriptive statistics method based largely on the Traditional Descriptive statistics method to determine the most suitable factors to cooperate with The Competitiveness of The Logistics Enterprises in Mekong Delta, Vietnam. This method is built on improving the content of the data collection process to integrate considering the requirements from the FISM method to conduct only one survey campaign to collect data instead of having to divided into many levels of implementation because the requirements for each method are not the same. The results of IDS analysis will be calculated by SPSS software and the order of analysis will be explained as following contents.

\section{A.l Cronbach's Alpha}

Testing the reliability of Cronbach's Alpha scale is a test that reflects the close correlation between observed variables in the same factor. It shows which of the observed variables of a factor has contributed to the measure of the factor concept. The Cronbach's Alpha results of the good factor show that the observed variables measuring the factor are reasonable, showing the characteristics of the parent factor.

Cronbach's Alpha coefficient has a variable value in the interval $[0,1]$. In theory, the higher this coefficient, the higher the reliability of the scale. However, when Cronbach's Alpha coefficient is too large (about 0.95 or more), it shows that there are many variables in the scale that do not differ from each other, this phenomenon is called overlap in the scale (Nunnally, 1978) [25]. When evaluating the reliability of the scale, we need to consider the following criteria:

- - If a measurement variable has a correlation coefficient of the total variable (Corrected Item - Total Correlation) greater than or equal to 0.3 , that variable meets the requirements.

- - Value of Cronbach's Alpha coefficient:

$+\quad$ From 0.8 to close to 1: very good scale;

$+\quad$ From 0.7 to close to 0.8: good usability scale;

$+\quad$ From 0.6 and up: qualifying scale.

- Cronbach's Alpha If Item Deleted: when the Cronbach's Alpha If Item Deleted value is greater than the group's Cronbach's Alpha coefficient, we consider this type of observed variable.

However, this is not the main criterion to evaluate the reliability of the scale, in some cases we can also consider keeping the observed variable when Cronbach's Alpha If Item Deleted coefficient is larger than Cronbach's Alpha coefficient. based on the researcher's reasoning.

In this part, Cronbach's Alpha (CsA) is used to test the reliability of each group in 7 groups of factors including REP, CUS, INF, EAS, QLS, TRA, TIM (see table 1).

Table 1.Factors belongs in LPI

\begin{tabular}{cll}
\hline Group Factor & Name of Factors \\
\hline REP & REP1 & Geographic spread \\
REP2 & Experience as a 3PL \\
REP3 & Focus on specific industry \\
REP4 & Range of services provider \\
REP5 & $\begin{array}{l}\text { Corporate culture (human factors } \\
\text { and customer experience) }\end{array}$ \\
\hline TIM & TIM1 & $\begin{array}{l}\text { Delivery time on the schedule } \\
\text { TIM2 }\end{array}$ \\
$\begin{array}{l}\text { Fast delivery time, before } \\
\text { appointment } \\
\text { Time that vehicles is kept at the } \\
\text { place of packing } \\
\text { TIM3 }\end{array}$ \\
TIM4 & $\begin{array}{l}\text { Seamless connectivity between } \\
\text { different vehicles }\end{array}$ \\
\hline CUS & CUS1 & $\begin{array}{l}\text { Speed of customs clearance } \\
\text { The customs process is clearly } \\
\text { carried out transparently }\end{array}$
\end{tabular}


CUS3 Customs clearance is fully prepared

CUS4 Tax solution for force majeure risks of goods

EAS EAS1 Level of price competition with
other competitors

EAS2 How easy it is to arrange shipments with good prices

EAS3 Appropriate price of service quality

\begin{tabular}{lll}
\hline INF & INF1 & $\begin{array}{l}\text { Financial capacity of logistics } \\
\text { company } \\
\text { Capacity of logistics company to } \\
\text { supply equipment (e.g. warehousing, } \\
\text { means of transport, handling } \\
\text { equipment) } \\
\text { Management capacity of logistic }\end{array}$ \\
INF3 & $\begin{array}{l}\text { Resources of logistics company } \\
\text { INF4 }\end{array}$ \\
INF5 & $\begin{array}{l}\text { Professional qualifications of } \\
\text { logistics staff }\end{array}$ \\
\hline QLS & QLS1 & $\begin{array}{l}\text { Ability to provide package logistics } \\
\text { services of the company }\end{array}$ \\
QLS2 & $\begin{array}{l}\text { Good customer support } \\
\text { QLS3 }\end{array}$ & $\begin{array}{l}\text { Satisfactory settlement of customer } \\
\text { complaints }\end{array}$ \\
QLS4 & Quality of service as committed \\
QLS5 & Reliability and stability of Service \\
\hline TRA & TRA1 & $\begin{array}{l}\text { The ability to connect order } \\
\text { information between the logistic } \\
\text { company and the customer } \\
\text { Exact shipping schedule }\end{array}$ \\
TRA3 & Good order tracking ability \\
& &
\end{tabular}

The CsA 's test process have shown that all results of The factors which include "Reputation" (REP1 to REP5), "Custom" (CUS1 to CUS4), "Infrastructure" (INF1 to INF5), "Ease of arranging shipments" (EAS1 to EAS3), "Qualities of logistic services" (QLS1 to QLS5), "Tracking and Tracing" (TRA1 to TRA3) and "Timeliness" (TIM1 to TIM4), have the Corrected Item - total Correlation values are larger than 0.3 and all CsA are larger than 0.6 , so they satisfy the conditions for factor analysis. The detail values will be shown by table 2 in which the data are collected in MD. Therefore, these variables were all used in the subsequent EFA analysis. CsA coefficient of the scale is equal to 0.720 shows that the scale has high reliability and is accepted to measure the competitiveness of logistics enterprises in the MD.

Table 2. The synthesized CsA coefficient

\begin{tabular}{lcccc}
\hline & $\begin{array}{c}\text { Scale } \\
\text { Mean if } \\
\text { Item } \\
\text { Deleted }\end{array}$ & $\begin{array}{c}\text { Scale } \\
\text { if Item } \\
\text { Deleted }\end{array}$ & $\begin{array}{c}\text { Corrected } \\
\text { Item-Total } \\
\text { Correlation }\end{array}$ & $\begin{array}{c}\text { CsA if } \\
\text { Item } \\
\text { Deleted }\end{array}$ \\
\hline Reputation & & & & 0.896 \\
\hline REP1 & 16.09 & 6.61 & 0.716 & 0.883 \\
REP2 & 15.95 & 7.339 & 0.723 & 0.878 \\
REP3 & 15.87 & 6.746 & 0.808 & 0.858 \\
REP4 & 15.96 & 6.933 & 0.786 & 0.863 \\
\hline
\end{tabular}

\begin{tabular}{|c|c|c|c|c|}
\hline REP5 & 15.82 & 7.519 & 0.703 & 0.882 \\
\hline Custom & & & & 0.913 \\
\hline CUS1 & 11.65 & 5.731 & 0.751 & 0.905 \\
\hline CUS2 & 11.53 & 5.121 & 0.817 & 0.882 \\
\hline CUS3 & 11.43 & 4.853 & 0.852 & 0.869 \\
\hline CUS4 & 11.6 & 5.27 & 0.795 & 0.89 \\
\hline \multicolumn{4}{|l|}{ Infrastructure } & 0.884 \\
\hline INF1 & 13.34 & 7.648 & 0.685 & 0.867 \\
\hline INF2 & 13.64 & 7.208 & 0.635 & 0.88 \\
\hline INF3 & 13.39 & 6.873 & 0.804 & 0.839 \\
\hline INF4 & 13.42 & 6.72 & 0.809 & 0.837 \\
\hline INF5 & 13.39 & 7.373 & 0.681 & 0.867 \\
\hline \multicolumn{4}{|c|}{ Ease of arranging shipments } & 0.917 \\
\hline EAS1 & 6.14 & 3.124 & 0.848 & 0.87 \\
\hline EAS2 & 6 & 3.079 & 0.774 & 0.927 \\
\hline EAS3 & 6.04 & 2.722 & 0.881 & 0.838 \\
\hline \multicolumn{4}{|c|}{ Qualities of logistics services } & 0.895 \\
\hline QLS1 & 13.9 & 8.7 & 0.648 & 0.891 \\
\hline QLS2 & 13.69 & 7.559 & 0.779 & 0.863 \\
\hline QLS3 & 13.86 & 8.15 & 0.703 & 0.88 \\
\hline QLS4 & 13.87 & 7.825 & 0.77 & 0.865 \\
\hline QLS5 & 13.78 & 7.49 & 0.811 & 0.856 \\
\hline \multicolumn{4}{|c|}{ Tracking and Tracing } & 0.883 \\
\hline TRA1 & 6.47 & 2.936 & 0.769 & 0.839 \\
\hline TRA2 & 6.44 & 2.934 & 0.758 & 0.848 \\
\hline TRA3 & 6.44 & 2.539 & 0.799 & 0.814 \\
\hline \multicolumn{4}{|l|}{ Timeliness } & 0.928 \\
\hline TIM1 & 9.6 & 6.217 & 0.833 & 0.906 \\
\hline TIM2 & 9.9 & 6.015 & 0.836 & 0.906 \\
\hline TIM3 & 9.88 & 6.105 & 0.841 & 0.904 \\
\hline TIM4 & 9.7 & 6.396 & 0.821 & 0.911 \\
\hline \multicolumn{4}{|c|}{ Logistics Competitiveness } & 0.72 \\
\hline LC1 & 7.29 & 1.365 & 0.769 & 0.393 \\
\hline $\mathrm{LC} 2$ & 6.87 & 1.272 & 0.456 & 0.778 \\
\hline LC3 & 7.43 & 1.617 & 0.464 & 0.718 \\
\hline
\end{tabular}

Source: The results are synthesized by Authors

\section{A.2 Exploratory Factor Analysis (EFA)}

Commenting on the results after analyzing EFA, KMO coefficients, and Bartlett's Test are all satisfactory through four runs. However, the variables that were removed at the first analysis were the variables INF1, INF3, INF4, INF5, QLS1, QLS2, QLS3, QLS4, QLS5 because the load factor was less than 0.65 . Next, in the second and third analyses, remove some unsatisfactory variables such as TRA3, INF2, and TRA1 because the load factor is less than 0.65. All observed variables with the same properties converge on one factor, demonstrating the satisfaction of the convergence value in EFA. According to the table of rotation matrix results, variables in the same column and variables with discriminant values that converge on four new factors are distinguished from each other and separated into separate columns. With the 
fourth analysis, in factor one, the factor TIM is significant when conversing with each other and the variable TRA2 also belongs to the same group. It has the smallest load factor in factor one, although factor loading of TRA2 being larger than 0.65 is satisfactory. But TRA2 does not have the same meaning as the TIM factors, it should be discarded. Finally, in the fifth analysis, all variables met the conditions.

After analyzing EFA over 4 runs and removing bad variables, the final EFA results are presented in tables 4.18, 4.19 and 4.2. The results show that the KMO value of 0.796 is good - a sufficient condition for factor analysis to be appropriate. The Bartlett test's significance being less than 0.05 which means that the variables are correlated with each other. There are 29 observed variables were included in the analysis. As a result, 16 observed variables were drawn into four factors, respectively: REP, CUS, EAS, TIM with a total variance of $79.793 \%$, which found the EFA model to be appropriate. Eigenvalues of all four factors are greater than 1, so they should be kept in the model. Therefore, these four factors qualify for the next analysis step. The results of Exploratory Factor Analysis for KMO and Bartlett's Test and Rotated Component Matrix will be shown in tables 3 - 4 .

Table 3. Exploratory Factor Analysis

KMO and Bartlett's Test

Kaiser-Meyer-Olkin Measure of Sampling 0.796

Adequacy.

\begin{tabular}{|c|c|c|}
\hline \multirow{3}{*}{$\begin{array}{l}\text { Bartlett's Test of } \\
\text { Sphericity }\end{array}$} & Approx. Chi-Square & 981.075 \\
\hline & $\mathrm{df}$ & 120 \\
\hline & Sig. & 0.000 \\
\hline
\end{tabular}

Table 4. Rotated Component Matrix

\begin{tabular}{|c|c|c|c|c|}
\hline & \multicolumn{3}{|c|}{ Component } & \multirow[b]{2}{*}{4} \\
\hline & 1 & 2 & 3 & \\
\hline REP3 & .852 & & & \\
\hline REP2 & .833 & & & \\
\hline REP4 & .830 & & & \\
\hline REP1 & .824 & & & \\
\hline REP5 & .736 & & & \\
\hline TIM2 & & .889 & & \\
\hline TIM3 & & .883 & & \\
\hline TIM1 & & .849 & & \\
\hline TIM4 & & .832 & & \\
\hline CUS2 & & & .897 & \\
\hline CUS3 & & & .887 & \\
\hline CUS4 & & & .809 & \\
\hline CUS1 & & & .769 & \\
\hline EAS1 & & & & .915 \\
\hline EAS3 & & & & .862 \\
\hline
\end{tabular}

EAS2 .799

Then, 16 factors from CsA and EFA analysis results will be combined with in-depth interviews with logistics experts. These factors are summarized in the table 5.

Table 5. Factors after Exploratory Factor Analysis

\begin{tabular}{|c|c|c|}
\hline Group & Factor & Name of Factors \\
\hline \multirow{5}{*}{ Reputation } & REP1 & Geographic spread \\
\hline & REP2 & Experience as a $3 \mathrm{PL}$ \\
\hline & REP3 & Focus on specific industry \\
\hline & REP4 & Range of services provider \\
\hline & REP5 & $\begin{array}{l}\text { Corporate culture (human factors } \\
\text { and customer experience) }\end{array}$ \\
\hline \multirow{4}{*}{ Timeliness } & TIM1 & Delivery time on the schedule \\
\hline & TIM2 & $\begin{array}{l}\text { Fast delivery time, before } \\
\text { appointment }\end{array}$ \\
\hline & TIM3 & $\begin{array}{l}\text { Time that vehicles is kept at the } \\
\text { place of packing }\end{array}$ \\
\hline & TIM4 & $\begin{array}{l}\text { Seamless connectivity between } \\
\text { different vehicles }\end{array}$ \\
\hline \multirow{4}{*}{ Customs } & CUS1 & Speed of customs clearance \\
\hline & CUS2 & $\begin{array}{l}\text { The customs process is clearly } \\
\text { carried out transparently }\end{array}$ \\
\hline & CUS3 & Customs clearance is fully prepared \\
\hline & CUS4 & $\begin{array}{l}\text { Tax solution for force majeure risks } \\
\text { of goods }\end{array}$ \\
\hline \multirow{3}{*}{$\begin{array}{l}\text { Ease of } \\
\text { arranging } \\
\text { shipments }\end{array}$} & EAS1 & $\begin{array}{l}\text { Level of price competition with } \\
\text { other competitors }\end{array}$ \\
\hline & EAS2 & $\begin{array}{l}\text { How easy it is to arrange shipments } \\
\text { with good prices }\end{array}$ \\
\hline & EAS3 & Appropriate price of service quality \\
\hline
\end{tabular}

\section{B. Using FISM-FMICMAC to cluster Enablers}

To establish a SSIM, data of the improved descriptive statistics step will be combined with the deeply interview process of a council including 10 experts/researchers who have managed/operated logistics' solutions. Then, the integration of the Fuzzy Linguistic Scale (FLS) on This SSIM is conducted to create the ASSIM.

In this study, 16 enablers which are mentioned under the trapezoidal fuzzy set. Defuzzification and implementation method is adopted by Savitha and George (2017)[13], Nguyen et al. (2021) [17] from the fuzzy numbers in Table 6. 
Table 6. Fuzzy linguistic scale

\begin{tabular}{|c|c|c|c|}
\hline $\begin{array}{c}\text { Linguistic } \\
\text { description }\end{array}$ & Notation & TFN & $\begin{array}{c}\text { Influence } \\
\text { scope }\end{array}$ \\
\hline $\begin{array}{c}\text { Extremely } \\
\text { insignificant }\end{array}$ & $\mathrm{NO}$ & $\begin{array}{c}(0.00,0.05 \\
0.15,0.25)\end{array}$ & 0 \\
\hline Insignificant & VL & $\begin{array}{c}(0.15,0.25 \\
0.35,0.45)\end{array}$ & 1 \\
\hline $\begin{array}{l}\text { Equally } \\
\text { significant }\end{array}$ & $\mathrm{L}$ & $\begin{array}{c}(0.35,0.45 \\
0.55,0.65)\end{array}$ & 2 \\
\hline $\begin{array}{c}\text { Moderately } \\
\text { significant }\end{array}$ & $\mathrm{H}$ & $\begin{array}{c}(0.55,0.65 \\
0.75,0.85)\end{array}$ & 3 \\
\hline $\begin{array}{l}\text { Extremely } \\
\text { significant }\end{array}$ & VH & $\begin{array}{c}(0.75,0.85 \\
0.95,1.00)\end{array}$ & 4 \\
\hline
\end{tabular}

In addition, the Fuzzy linguistic scale is also interpreted with the combination of the effect level in the pair-wise comparison from the ISM method, namely the values of "V", "A", "X", "O" with the interaction of "VL", "L", "H", "VH". For example, Fuzzy linguistic scale values will be displayed as "V(H)", "V(L)" instead of just "H" and "L". By the way, the Fuzzy linguistic values that are used in this study, are shown in Table 7.

Table 7. Fuzzy trapezoidal linguistic values

\begin{tabular}{lcc}
\hline Notations & $\mathbf{i}, \mathbf{j}$ & $\mathbf{j}, \mathbf{i}$ \\
\hline $\mathrm{V}(\mathrm{VH})$ & $0.75,0.85,0.95,1.00$ & $0.00,0.05,0.15,0.25$ \\
$\mathrm{~V}(\mathrm{H})$ & $0.55,0.65,0.75,0.85$ & $0.00,0.05,0.15,0.25$ \\
$\mathrm{~V}(\mathrm{~L})$ & $0.35,0.45,0.55,0.65$ & $0.00,0.05,0.15,0.25$ \\
$\mathrm{~V}(\mathrm{VL})$ & $0.15,0.25,0.35,0.45$ & $0.00,0.05,0.15,0.25$ \\
$\mathrm{~A}(\mathrm{VH})$ & $0.00,0.05,0.15,0.25$ & $0.75,0.85,0.95,1.00$ \\
$\mathrm{~A}(\mathrm{H})$ & $0.00,0.05,0.15,0.25$ & $0.55,0.65,0.75,0.85$ \\
$\mathrm{~A}(\mathrm{~L})$ & $0.00,0.05,0.15,0.25$ & $0.35,0.45,0.55,0.65$ \\
\hline
\end{tabular}

\begin{tabular}{|c|c|c|}
\hline $\mathrm{A}(\mathrm{VL})$ & $0.00,0.05,0.15,0.25$ & $0.15,0.25,0.35,0.45$ \\
\hline $\mathrm{X}(\mathrm{VH})$ & $0.75,0.85,0.95,1.00$ & $0.75,0.85,0.95,1.00$ \\
\hline $\mathrm{X}(\mathrm{H})$ & $0.55,0.65,0.75,0.85$ & $0.55,0.65,0.75,0.85$ \\
\hline $\mathrm{X}(\mathrm{L})$ & $0.35,0.45,0.55,0.65$ & $0.35,0.45,0.55,0.65$ \\
\hline $\mathrm{X}(\mathrm{VL})$ & $0.15,0.25,0.35,0.45$ & $0.15,0.25,0.35,0.45$ \\
\hline $\mathrm{X}(\mathrm{VH}, \mathrm{H})$ & $0.75,0.85,0.95,1.00$ & $0.55,0.65,0.75,0.85$ \\
\hline $\mathrm{X}(\mathrm{VH}, \mathrm{L})$ & $0.75,0.85,0.95,1.00$ & $0.35,0.45,0.55,0.65$ \\
\hline $\mathrm{X}(\mathrm{VH}, \mathrm{VL})$ & $0.75,0.85,0.95,1.00$ & $0.15,0.25,0.35,0.45$ \\
\hline $\mathrm{X}(\mathrm{H}, \mathrm{VH})$ & $0.55,0.65,0.75,0.85$ & $0.75,0.85,0.95,1.00$ \\
\hline $\mathrm{X}(\mathrm{H}, \mathrm{L})$ & $0.55,0.65,0.75,0.85$ & $0.35,0.45,0.55,0.65$ \\
\hline $\mathrm{X}(\mathrm{H}, \mathrm{VL})$ & $0.55,0.65,0.75,0.85$ & $0.15,0.25,0.35,0.45$ \\
\hline $\mathrm{X}(\mathrm{L}, \mathrm{VH})$ & $0.35,0.45,0.55,0.65$ & $0.75,0.85,0.95,1.00$ \\
\hline $\mathrm{X}(\mathrm{L}, \mathrm{H})$ & $0.35,0.45,0.55,0.65$ & $0.55,0.65,0.75,0.85$ \\
\hline $\mathrm{X}(\mathrm{L}, \mathrm{VL})$ & $0.35,0.45,0.55,0.65$ & $0.15,0.25,0.35,0.45$ \\
\hline $\mathrm{X}(\mathrm{VL}, \mathrm{VH})$ & $0.15,0.25,0.35,0.45$ & $0.75,0.85,0.95,1.00$ \\
\hline $\mathrm{X}(\mathrm{VL}, \mathrm{H})$ & $0.15,0.25,0.35,0.45$ & $0.55,0.65,0.75,0.85$ \\
\hline $\mathrm{X}(\mathrm{VL}, \mathrm{L})$ & $0.15,0.25,0.35,0.45$ & $0.35,0.45,0.55,0.65$ \\
\hline $\mathrm{O}(\mathrm{NO})$ & $0.00,0.05,0.15,0.25$ & $0.00,0.05,0.15,0.25$ \\
\hline
\end{tabular}

Following FISM process, the ASSIM will be established from the combination of the correlation analysis results by the IDS method step and the in-depth interviews with the logistics experts/managers in the MD region according to the Fuzzy trapezoidal linguistic values that are referred to table 7 . Accordingly, the results on the degree of pairwise comparison will be determined according to the "V(VH)" values and equivalent according to the specific meaning of each pairwise relationship. The full contents of ASSIM will then be considered from two different perspectives, namely for the remaining step of FISM process and FMICMAC methods, whose description is shown in table 8 .

Table 8. Aggregated SSIM

\section{REP1 REP2 REP3 REP4 REP5 CUS1 CUS2 CUS3 CUS4 EAS1 EAS2 EAS3 TIM1 TIM2 TIM3 TIM4}

\begin{tabular}{|c|c|c|c|c|c|c|c|c|c|c|c|c|c|c|c|c|}
\hline REP1 & 1 & $\mathrm{X}(\mathrm{H})$ & $\mathrm{X}(\mathrm{H})$ & $\mathrm{X}(\mathrm{H})$ & $\mathrm{X}(\mathrm{L})$ & $\mathrm{V}(\mathrm{VL})$ & $V(V L)$ & $\mathrm{V}(\mathrm{VL})$ & $\mathrm{V}(\mathrm{L})$ & $\mathrm{O}$ & $\mathrm{O}$ & $\mathrm{O}$ & $\mathrm{O}$ & $\mathrm{O}$ & $\mathrm{O}$ & $\mathrm{O}$ \\
\hline REP2 & $\mathrm{X}(\mathrm{H})$ & 1 & $\mathrm{X}(\mathrm{H})$ & $\mathrm{X}(\mathrm{H})$ & $\mathrm{X}(\mathrm{L})$ & $\mathrm{V}(\mathrm{L})$ & $\mathrm{V}(\mathrm{VL})$ & $\mathrm{V}(\mathrm{VL})$ & $\mathrm{V}(\mathrm{VL})$ & $\mathrm{O}$ & $\mathrm{O}$ & $\mathrm{O}$ & $\mathrm{O}$ & $\mathrm{O}$ & $\mathrm{O}$ & $\mathrm{O}$ \\
\hline REP3 & $\mathrm{X}(\mathrm{H})$ & $\mathrm{X}(\mathrm{H})$ & 1 & $\mathrm{X}(\mathrm{H})$ & $\mathrm{X}(\mathrm{H})$ & $\mathrm{V}(\mathrm{L})$ & $\mathrm{V}(\mathrm{VL})$ & $\mathrm{V}(\mathrm{VL})$ & $\mathrm{V}(\mathrm{L})$ & $\mathrm{O}$ & $\mathrm{O}$ & $\mathrm{O}$ & $\mathrm{O}$ & $\mathrm{O}$ & $\mathrm{O}$ & $\mathrm{O}$ \\
\hline REP4 & $\mathrm{X}(\mathrm{H})$ & $\mathrm{X}(\mathrm{H})$ & $\mathrm{X}(\mathrm{H})$ & 1 & $\mathrm{X}(\mathrm{H})$ & $\mathrm{V}(\mathrm{L})$ & $\mathrm{V}(\mathrm{VL})$ & $\mathrm{V}(\mathrm{L})$ & $\mathrm{V}(\mathrm{L})$ & $\mathrm{O}$ & $\mathrm{O}$ & $\mathrm{O}$ & $\mathrm{O}$ & $\mathrm{O}$ & $\mathrm{O}$ & $\mathrm{O}$ \\
\hline REP5 & $\mathrm{X}(\mathrm{L})$ & $\mathrm{X}(\mathrm{L})$ & $\mathrm{X}(\mathrm{H})$ & $\mathrm{X}(\mathrm{H})$ & 1 & $\mathrm{~V}(\mathrm{~L})$ & $\mathrm{V}(\mathrm{L})$ & $\mathrm{V}(\mathrm{L})$ & $\mathrm{V}(\mathrm{L})$ & $\mathrm{O}$ & $\mathrm{O}$ & $\mathrm{O}$ & $\mathrm{O}$ & $\mathrm{O}$ & $\mathrm{O}$ & $\mathrm{O}$ \\
\hline CUS1 & $\mathrm{A}(\mathrm{VL})$ & $\mathrm{A}(\mathrm{L})$ & $\mathrm{A}(\mathrm{L})$ & $\mathrm{A}(\mathrm{L})$ & $\mathrm{A}(\mathrm{L})$ & 1 & $\mathrm{X}(\mathrm{H})$ & $\mathrm{X}(\mathrm{H})$ & $\mathrm{X}(\mathrm{H})$ & $\mathrm{O}$ & $\mathrm{O}$ & $\mathrm{O}$ & $\mathrm{O}$ & $\mathrm{O}$ & $\mathrm{O}$ & $\mathrm{O}$ \\
\hline
\end{tabular}




\begin{tabular}{|c|c|c|c|c|c|c|c|c|c|c|c|c|c|c|c|c|}
\hline CUS2 & $\mathrm{A}(\mathrm{VL})$ & $\mathrm{A}(\mathrm{VL})$ & $\mathrm{A}(\mathrm{VL})$ & $\mathrm{A}(\mathrm{VL})$ & $\mathrm{A}(\mathrm{L})$ & $\mathrm{X}(\mathrm{H})$ & 1 & $\mathrm{X}(\mathrm{VH})$ & $\mathrm{X}(\mathrm{H})$ & $\mathrm{O}$ & $\mathrm{O}$ & $\mathrm{O}$ & $\mathrm{O}$ & $\mathrm{X}(\mathrm{VL})$ & $\mathrm{O}$ & $\mathrm{O}$ \\
\hline CUS3 & $\mathrm{A}(\mathrm{VL})$ & $\mathrm{A}(\mathrm{VL})$ & $\mathrm{A}(\mathrm{VL})$ & $\mathrm{A}(\mathrm{L})$ & $\mathrm{A}(\mathrm{L})$ & $\mathrm{X}(\mathrm{H})$ & $\mathrm{X}(\mathrm{VH})$ & 1 & $\mathrm{X}(\mathrm{VH})$ & $\mathrm{O}$ & $\mathrm{X}(\mathrm{VL})$ & $\mathrm{O}$ & $\mathrm{X}(\mathrm{VL})$ & $\mathrm{X}(\mathrm{VL})$ & $\mathrm{X}(\mathrm{VL})$ & $\mathrm{X}(\mathrm{VL})$ \\
\hline CUS4 & $A(L)$ & $\mathrm{A}(\mathrm{VL})$ & $\mathrm{A}(\mathrm{L})$ & $\mathrm{A}(\mathrm{L})$ & $\mathrm{A}(\mathrm{L})$ & $\mathrm{X}(\mathrm{H})$ & $\mathrm{X}(\mathrm{H})$ & $\mathrm{X}(\mathrm{VH})$ & 1 & $\mathrm{O}$ & $\mathrm{X}(\mathrm{VL})$ & $\mathrm{O}$ & $\mathrm{X}(\mathrm{VL})$ & $\mathrm{X}(\mathrm{VL})$ & $\mathrm{O}$ & $\mathrm{X}(\mathrm{VL})$ \\
\hline EAS1 & $\mathrm{O}$ & $\mathrm{O}$ & $\mathrm{O}$ & $\mathrm{O}$ & $\mathrm{O}$ & $\mathrm{O}$ & $\mathrm{O}$ & $\mathrm{O}$ & $\mathrm{O}$ & 1 & $\mathrm{X}(\mathrm{H})$ & $\mathrm{X}(\mathrm{VH})$ & $\mathrm{X}(\mathrm{L})$ & $\mathrm{X}(\mathrm{L})$ & $\mathrm{X}(\mathrm{L})$ & $\mathrm{X}(\mathrm{L})$ \\
\hline EAS2 & $\mathrm{O}$ & $\mathrm{O}$ & $\mathrm{O}$ & $\mathrm{O}$ & $\mathrm{O}$ & $\mathrm{O}$ & $\mathrm{O}$ & $\mathrm{X}(\mathrm{VL})$ & $X(V L)$ & $X(H)$ & 1 & $\mathrm{X}(\mathrm{VH})$ & $X(L)$ & $\mathrm{X}(\mathrm{L})$ & $\mathrm{X}(\mathrm{L})$ & $\mathrm{X}(\mathrm{L})$ \\
\hline EAS3 & $\mathrm{O}$ & $\mathrm{O}$ & $\mathrm{O}$ & $\mathrm{O}$ & $\mathrm{O}$ & $\mathrm{O}$ & $\mathrm{O}$ & $\mathrm{O}$ & $\mathrm{O}$ & $\mathrm{X}(\mathrm{VH})$ & $\mathrm{X}(\mathrm{VH})$ & 1 & $\mathrm{X}(\mathrm{H})$ & $\mathrm{X}(\mathrm{L})$ & $\mathrm{X}(\mathrm{L})$ & $\mathrm{X}(\mathrm{H})$ \\
\hline TIMI & $\mathrm{O}$ & $\mathrm{O}$ & $\mathrm{O}$ & $\mathrm{O}$ & $\mathrm{O}$ & $\mathrm{O}$ & $\mathrm{O}$ & $\mathrm{X}(\mathrm{VL})$ & $X(V L)$ & $X(L)$ & $\mathrm{X}(\mathrm{L})$ & $\mathrm{X}(\mathrm{H})$ & 1 & $\mathrm{X}(\mathrm{VH})$ & $\mathrm{X}(\mathrm{VH})$ & $\mathrm{X}(\mathrm{H})$ \\
\hline TIM2 & $\mathrm{O}$ & $\mathrm{O}$ & $\mathrm{O}$ & $\mathrm{O}$ & $\mathrm{O}$ & $\mathrm{O}$ & $\mathrm{X}(\mathrm{VL})$ & $\mathrm{X}(\mathrm{VL})$ & $X(V L)$ & $X(L)$ & $\mathrm{X}(\mathrm{L})$ & $\mathrm{X}(\mathrm{L})$ & $\mathrm{X}(\mathrm{VH})$ & 1 & $\mathrm{X}(\mathrm{VH})$ & $X(H)$ \\
\hline TIM3 & $\mathrm{O}$ & $\mathrm{O}$ & $\mathrm{O}$ & $\mathrm{O}$ & $\mathrm{O}$ & $\mathrm{O}$ & $\mathrm{O}$ & $\mathrm{X}(\mathrm{VL})$ & $\mathrm{O}$ & $\mathrm{X}(\mathrm{L})$ & $\mathrm{X}(\mathrm{L})$ & $\mathrm{X}(\mathrm{L})$ & $\mathrm{X}(\mathrm{VH})$ & $\mathrm{X}(\mathrm{VH})$ & 1 & $\mathrm{X}(\mathrm{VH})$ \\
\hline TIM4 & $\mathrm{O}$ & $\mathrm{O}$ & $\mathrm{O}$ & $\mathrm{O}$ & $\mathrm{O}$ & $\mathrm{O}$ & $\mathrm{O}$ & $\mathrm{X}(\mathrm{VL})$ & $X(V L)$ & $X(\mathrm{~L})$ & $\mathrm{X}(\mathrm{L})$ & $\mathrm{X}(\mathrm{H})$ & $\mathrm{X}(\mathrm{H})$ & $\mathrm{X}(\mathrm{H})$ & $\mathrm{X}(\mathrm{VH})$ & 1 \\
\hline
\end{tabular}

According to the next step in FISM, the IFRM using Linguistic Variables (LVs) will be built by the combined comparison between tables 6-8. Specifically, after comparing the fuzzy trapezoidal language values between Table 6 and Table 7, The symbols between these two tables will be converted into rules with the symbols in Table 6 being equivalent to the symbols in Table 7 under the same conditions of Fuzzy trapezoidal linguistic values. For example, the value $(0.00,0.05,0.15,0.25)$ will be represented by $\mathrm{A}(\mathrm{VH})$ in Table 7 or NO in Table 6. Therefore, "A(VH)" is similar as "NO". This convert rule will then be used to replace the notation in table 8 to form a new matrix that is shown in table 9.

The results of Table 9 will now only be the occurrence of L, VL, H, VH, A and NO (Luo et al., 2018) for the pairwise comparisons. These symbols are then checked during a comparison with Table 6 to convert the state from literal to binary " 0 " and " 1 " and then integrated with the transitivity relationships review process. to form the FDRM (see Table 10) that is then used for ordering the level partitions (LPs).
LPs are the complicated process based on the Reachability (Re) and Antecedent (Ante) sets, which are other names of Driving (Dr) and dependent (De) factors, respectively. Besides, the Intersection (Inte) sets is the sets containing all factors of Re set that also belong to Ante set. However, the contents of Inte sets are only established step by step. For example, in first step, the Inte factors will put on the Level I which must satisfy the condition of their number of factors in Inte column are lowest and no presence in these of others. Once the top-level effected factors are identified, the relative factors in the columns of Re, Ante and Inte are removed from the next iteration, and a similar procedure leads to final iteration leading to the last level (Level VI in this research). The process of this level partition are implemented following the guide of Warfield (1974) and its results will be shown in Table 11. [26] Then, FISM hierarchy model is drawn by the level partitioning step. This model will be used to complement the results of the FMICMAC (see Figure 3).

Table 9. The IFRM using LVs

REP1 REP2 REP3 REP4 REP5 CUS1 CUS2 CUS3 CUS4 EAS1 EAS2 EAS3 TIM1 TIM2 TIM3 TIM4

\begin{tabular}{lcccccccccccccccc}
\hline $\boldsymbol{R E P 1}$ & 1 & H & H & H & L & VL & VL & VL & L & NO & NO & NO & NO & NO & NO & NO \\
$\boldsymbol{R E P 2}$ & H & 1 & H & H & L & L & VL & VL & VL & NO & NO & NO & NO & NO & NO & NO \\
$\boldsymbol{R E P 3 ~}$ & H & H & 1 & H & H & L & VL & VL & L & NO & NO & NO & NO & NO & NO & NO \\
$\boldsymbol{R E P 4 ~}$ & H & H & H & 1 & H & L & VL & L & L & NO & NO & NO & NO & NO & NO & NO \\
$\boldsymbol{R E P 5 ~}$ & L & L & H & H & 1 & L & L & L & L & NO & NO & NO & NO & NO & NO & NO \\
$\boldsymbol{C U S 1 ~}$ & NO & NO & NO & NO & NO & 1 & H & H & H & NO & NO & NO & NO & NO & NO & NO \\
$\boldsymbol{C U S 2 ~}$ & NO & NO & NO & NO & NO & H & 1 & VH & H & NO & NO & NO & NO & VL & NO & NO \\
$\boldsymbol{C U S 3 ~}$ & NO & NO & NO & NO & NO & H & VH & 1 & VH & NO & VL & NO & VL & VL & VL & VL \\
$\boldsymbol{C U S 4 ~}$ & NO & NO & NO & NO & NO & H & H & VH & 1 & NO & VL & NO & VL & VL & NO & VL \\
$\boldsymbol{E A S 1 ~}$ & NO & NO & NO & NO & NO & NO & NO & NO & NO & 1 & H & VH & L & L & L & L
\end{tabular}




\begin{tabular}{lllllllllllllllllc}
$\boldsymbol{E A S 2}$ & NO & NO & NO & NO & NO & NO & NO & VL & VL & H & 1 & VH & L & L & L & L \\
$\boldsymbol{E A S 3}$ & NO & NO & NO & NO & NO & NO & NO & NO & NO & VH & VH & 1 & H & L & L & H \\
TIM1 & NO & NO & NO & NO & NO & NO & NO & VL & VL & L & L & H & 1 & VH & VH & H \\
TIM2 & NO & NO & NO & NO & NO & NO & VL & VL & VL & L & L & L & VH & 1 & VH & H \\
TIM3 & NO & NO & NO & NO & NO & NO & NO & VL & NO & L & L & L & VH & VH & 1 & VH \\
TIM4 & NO & NO & NO & NO & NO & NO & NO & VL & VL & L & L & H & H & H & VH & 1 \\
\hline
\end{tabular}

Table 10. Final defuzzied reachability matrix with transitive links

\begin{tabular}{|c|c|c|c|c|c|c|c|c|c|c|c|c|c|c|c|c|c|}
\hline $\begin{array}{l}\text { Impact } \\
\text { of } \mathbf{i} \text { on } j\end{array}$ & REP1 & REP2 & REP3 & REP5 & EAS1 & EAS3 & TIM3 & 3 REP4 & CUS1 & CUS2 & CUS3 & CUS4 & EAS2 & TIM1' & TIM2 & TIM4 & Dr \\
\hline CUS1 & 0 & 0 & 0 & 0 & 0 & 0 & 0 & 0 & 1 & 1 & 1 & 1 & $1 *$ & $1^{*}$ & $1^{*}$ & $1 *$ & 8 \\
\hline CUS4 & 0 & 0 & 0 & 0 & 0 & 0 & 0 & 0 & 1 & 1 & 1 & 1 & 1 & 1 & 1 & 1 & 8 \\
\hline CUS2 & 0 & 0 & 0 & 0 & $1^{*}$ & $1^{*}$ & $1^{*}$ & 0 & 1 & 1 & 1 & 1 & $1^{*}$ & $1^{*}$ & 1 & $1^{*}$ & 11 \\
\hline CUS3 & 0 & 0 & 0 & 0 & $1^{*}$ & $1^{*}$ & 1 & 0 & 1 & 1 & 1 & 1 & 1 & 1 & 1 & 1 & 11 \\
\hline EAS1 & 0 & 0 & 0 & 0 & 1 & 1 & 1 & $1^{*}$ & $1^{*}$ & $1^{*}$ & $1^{*}$ & $1^{*}$ & 1 & 1 & 1 & 1 & 12 \\
\hline EAS2 & 0 & 0 & 0 & 0 & 1 & 1 & 1 & $1^{*}$ & $1^{*}$ & $1^{*}$ & 1 & 1 & 1 & 1 & 1 & 1 & 12 \\
\hline EAS3 & 0 & 0 & 0 & 0 & 1 & 1 & 1 & 1 & $1^{*}$ & $1^{*}$ & $1^{*}$ & $1^{*}$ & 1 & 1 & 1 & 1 & 12 \\
\hline TIM1 & 0 & 0 & 0 & 0 & 1 & 1 & 1 & $1^{*}$ & $1^{*}$ & $1 *$ & 1 & 1 & 1 & 1 & 1 & 1 & 12 \\
\hline TIM2 & 0 & 0 & 0 & 0 & 1 & 1 & 1 & $1^{*}$ & $1^{*}$ & 1 & 1 & 1 & 1 & 1 & 1 & 1 & 12 \\
\hline TIM3 & 0 & 0 & 0 & 0 & 1 & 1 & 1 & $1^{*}$ & $1^{*}$ & $1^{*}$ & 1 & $1^{*}$ & 1 & 1 & 1 & 1 & 12 \\
\hline TIM4 & 0 & 0 & 0 & 0 & 1 & 1 & 1 & $1^{*}$ & 1 & 1 & 1 & 1 & 1 & 1 & 1 & 1 & 12 \\
\hline REP1 & 1 & 1 & 1 & 1 & 0 & 0 & 0 & 1 & 1 & 1 & 1 & 1 & $1^{*}$ & $1^{*}$ & $1^{*}$ & $1^{*}$ & 13 \\
\hline REP2 & 1 & 1 & 1 & 1 & 0 & 0 & 0 & 1 & 1 & 1 & 1 & 1 & $1^{*}$ & $1 *$ & $1^{*}$ & $1 *$ & 13 \\
\hline REP3 & 1 & 1 & 1 & 1 & 0 & 0 & 0 & 1 & 1 & 1 & 1 & 1 & $1^{*}$ & $1^{*}$ & $1^{*}$ & $1 *$ & 13 \\
\hline REP4 & 1 & 1 & 1 & 1 & 0 & 0 & 0 & 1 & 1 & 1 & 1 & 1 & $1^{*}$ & $1^{*}$ & $1 *$ & $1^{*}$ & 13 \\
\hline REP5 & 1 & 1 & 1 & 1 & 0 & 0 & 0 & 1 & 1 & 1 & 1 & 1 & $1^{*}$ & $1^{*}$ & $1^{*}$ & $1 *$ & 13 \\
\hline De & 5 & 5 & 5 & 5 & 9 & 9 & 9 & 12 & 16 & 16 & 16 & 16 & 16 & 16 & 16 & 16 & 130 \\
\hline
\end{tabular}

* Transitivity check

Table 11. Level partitioning of Characteristics

\begin{tabular}{lcccc}
\hline Enablers & Reachability & Antecedent & Intersection & Level \\
\hline REP1 & $2,3,4,5,6,7,8,9,11,13,14,16$ & $2,3,4,5$ & $2,3,4,5$ & I \\
REP2 & $1,3,4,5,6,7,8,9,11,13,14,16$ & $1,3,4,5$ & $1,3,4,5$ & I \\
REP3 & $1,2,4,5,6,7,8,9,11,13,14,16$ & $1,2,4,5$ & $1,2,4,5$ & I \\
REP5 & $1,2,3,4,6,7,8,9,11,13,14,16$ & $1,2,3,4$ & $1,2,3,4$ & I \\
REP4 & $1,2,3,5,6,7,8,9,11,13,14,16$ & $12,1,2,3,5,10,11,13,14,15,16$ & $11,13,14,16$ & II \\
CUS4 & $6,7,8,11,13,14,16$ & $1,2,3,4,5,6,7,11,13,14,10,12,15$ & 6,7 & III \\
\hline
\end{tabular}




\begin{tabular}{lcccc}
\hline CUS1 & $7,8,9,11,13,14,16$ & $1,2,3,4,5,6,7,8,9,10,11,12,13$ & 8,9 & IV \\
CUS2 & $6,8,9,14,10,12,15,11,13,14,16$ & $6,9,8,14,16,1,2,3,4,5,10,11,12,13,15$ & 10,12 & V \\
CUS3 & $6,7,9,11,13,14,15,16,10,12$ & $1,2,3,4,5,6,7,9,11,13,14,10,12$ & 10,12 & V \\
EAS1 & $11,12,13,14,15,16,4,6,7,8,9$ & $11,12,13,14,15,16,7,8$ & 12,15 & V \\
EAS2 & $8,9,10,12,13,14,15,16,4,6,7$ & $8,9,10,12,13,14,15,16,6,7,1,2,3,4,5$. & 10,12 & V \\
EAS3 & $4,10,11,13,14,15,16,6,7,8,9$ & $10,11,13,14,15,16,7,8$ & 10,15 & V \\
TIM3 & $7,8,9,10,11,12,13,14,16,4,6,7,9$ & $8,10,11,12,13,14,16,7$ & 10,12 & V \\
TIM1 & $8,9,10,11,12,14,15,16,4,6,7$ & $8,9,10,11,12,14,15,16,6,7,1,2,3,4,5$. & $10,12,15$ & VI \\
TIM2 & $7,8,9,10,11,12,13,15,16,4,6$ & $8,9,10,11,12,13,15,16,6,7,1,2,3,4,5,6$ & $10,12,15$ & VI \\
TIM4 & $6,7,8,9,10,11,12,13,14,15,4$ & $8,9,10,11,12,14,15,16,6,7,1,2,3,4,5$. & $10,12,15$ & VI \\
\hline
\end{tabular}

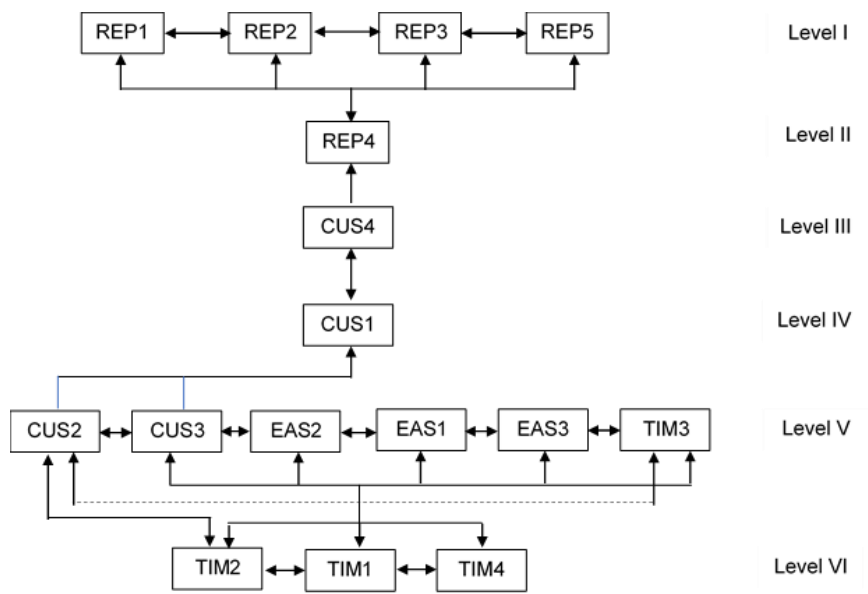

Figure 3. FISM hierarchy model

On the other hand of FMICMAC, the Initial FuzzyAggregated Reachability Matrix (IFARM) is established by replacing all notations in Table 8 by the relative values in table 7. For example, the notation of "X(H)" is become the value of $(0.55,0.65,0.75,0.85)$. These replacements will be implemented for all notations in table 8 , which is depicted in Table 12 .

The results of table 12 are summed by row and column, respectively. These total values are called by the factor's Driving (Dr) Power for the sum results of the rows and the factor's Dependent (De) Power for the sum results of the columns. In addition, these sums are still displayed in TFN format before they are defuzzied by the rule of Ghosh and Fedorowicz (2008) [27] as function (2)

$$
a_{i j}=\frac{2 l_{i j}+7 m_{i j}+7 n_{i j}+2 u_{i j}}{18} .
$$

where $a_{i j}$ is crisp value of defuzzification $(\mathrm{CV})$ for the $\mathrm{i}^{\text {th }}$ and the $\mathrm{j}^{\text {th }}$ factors and a TFN denoted as $\widetilde{a_{\imath \jmath}}=$ $\left(l_{i j}, m_{i j}, n_{i j}, u_{i j}\right)$.

For example, $\mathrm{X}(\mathrm{H})$ is represented by $a_{R E P 1 R E P 2}=$ $(0.55,0.65,0.75,0.85)$. Therefore, a crisp value of defuzzification for $\mathrm{X}(\mathrm{H})$ is calculated as follows:

$$
a_{R E P 1 R E P 2}=\frac{2 x 0.55+7 x 0.65+7 x 0.75+2 x 0.85}{18}=0.7
$$

In this methodology, the CVs of Dr and De powers will be determined on each factor. These values in the combination of Dr and De powers under TFN are shown in table 13. The CVs of Dr and De powers values for the considered factors will be aggregated to form the corresponding value pairs for each factor. These pairs of values are plotted in the point graph, in which each point will represent for the corresponding position of a factor on the graph (Figure 4). The vertical and horizontal axis of this point graph will be considered as the values of $\mathrm{Dr}$ and De powers, respectively. Then, the lines under vertical and horizontal shapes, whose purposes to separate the coverage all points area to 4 clusters in the graph, will be determined based on the average value determined based on the range on each pillar considered. The results are shown in Figure 4, the factors' points are divided into four region (clusters) which are as follows: autonomous, dependent, linkage and independent regions (clusters).

Table 12. The IFRM using Fuzzy number.

REP1 REP2 REP3 REP4 REP5 CUS1 CUS2 CUS3 CUS4 EAS1 EAS2 EAS3 TIM1 TIM2 TIM3 TIM4

$(0.55, \quad(0.55, \quad(0.55, \quad(0.35, \quad(0.15, \quad(0.15, \quad 0.15, \quad 0.35, \quad(0.00, \quad(0.00, \quad(0.00, \quad(0.00, \quad(0.00, \quad(0.00, \quad(0.00$

RE $\quad 1,1,1, \quad 0.65, \quad 0.65, \quad 0.65, \quad 0.45, \quad 0.25, \quad 0.25, \quad 0.25, \quad 0.45, \quad 0.05, \quad 0.05, \quad 0.05, \quad 0.05, \quad 0.05, \quad 0.05, \quad 0.05$,

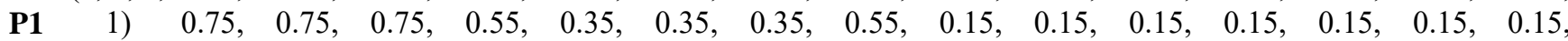

$\begin{array}{lllllllllllllll}0.85) & 0.85( & 0.85) & 0.65) & 0.45) & 0.45) & 0.45) & 0.65) & 0.25) & 0.25) & 0.25) & 0.25) & 0.25) & 0.25) & 0.25)\end{array}$

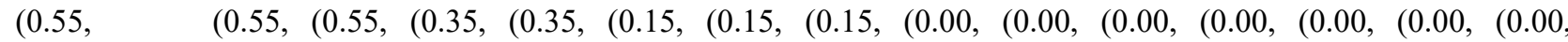

RE $\quad 0.65, \quad 1,1,1, \quad 0.65, \quad 0.65, \quad 0.45, \quad 0.45, \quad 0.25, \quad 0.25, \quad 0.25, \quad 0.05, \quad 0.05, \quad 0.05, \quad 0.05, \quad 0.05, \quad 0.05, \quad 0.05$,

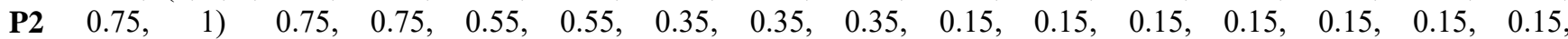

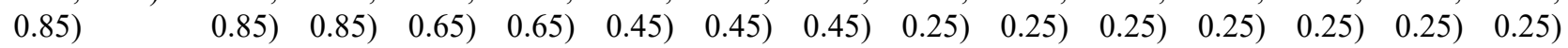


$(0.55,(0.55$,

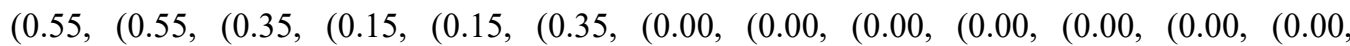

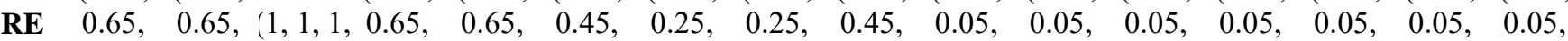

P3 $\quad 0.75, \quad 0.75, \quad 1) \quad 0.75, \quad 0.75, \quad 0.55, \quad 0.35, \quad 0.35, \quad 0.55,0.15, \quad 0.15, \quad 0.15, \quad 0.15, \quad 0.15, \quad 0.15, \quad 0.15$, $\begin{array}{lllllllllllllll}0.85) & 0.85) & 0.85) & 0.85) & 0.65) & 0.45) & 0.45) & 0.65) & 0.25) & 0.25) & 0.25) & 0.25) & 0.25) & 0.25) & 0.25)\end{array}$

$(0.55,(0.55,(0.55, \quad(0.55,(0.35,(0.15),(0.35),(0.35,(0.00),(0.00,(0.00,(0.00,(0.00),(0.00,(0.00$,

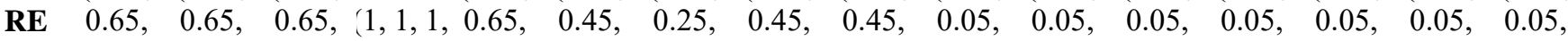

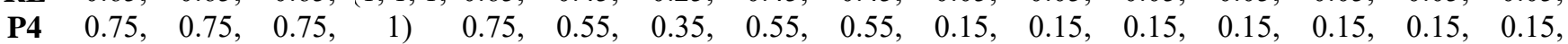
$\begin{array}{lllllllllllllll}0.85) & 0.85) & 0.85) & 0.85) & 0.65) & 0.45) & 0.65) & 0.65) & 0.25) & 0.25) & 0.25) & 0.25) & 0.25) & 0.25) & 0.25)\end{array}$

$(0.35,(0.35,(0.55),(0.55, \quad 0.35,(0.35,(0.35,(0.35,(0.00),(0.00,(0.00,(0.00),(0.00,(0.00,(0.00$,

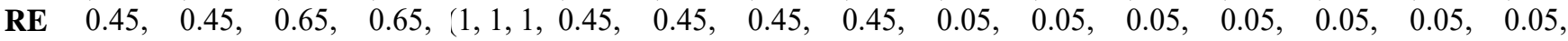

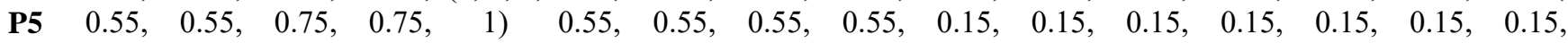
$\begin{array}{lllllllllllllll}0.65) & 0.65) & 0.85) & 0.85) & 0.65) & 0.65) & 0.65) & 0.65) & 0.25) & 0.25) & 0.25) & 0.25) & 0.25) & 0.25) & 0.25)\end{array}$

$(0.00,(0.00,(0.00,(0.00,(0.00, \quad) \quad(0.55),(0.55,(0.55,(0.00,(0.00),(0.00,(0.00,(0.00),(0.00,(0.00$,

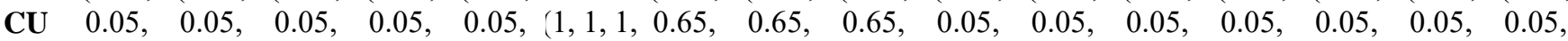

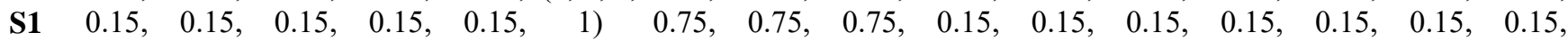
$\begin{array}{lllllllllllllll}0.25) & 0.25) & 0.25) & 0.25 & 0.25) & 0.85) & 0.85) & 0.85) & 0.25) & 0.25 & 0.25) & 0.25) & 0.25) & 0.25) & 0.25)\end{array}$

$(0.00,(0.00,(0.00,(0.00,(0.00,(0.55, \quad) \quad 0.75,(0.55,(0.00,(0.00,(0.00,(0.00,(0.15),(0.00,(0.00$,

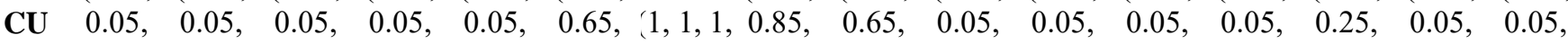

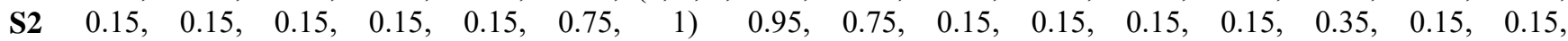

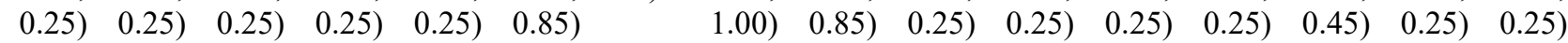

$(0.00,(0.00,(0.00),(0.00,(0.00,(0.55,(0.75, \quad 0.75,(0.00),(0.15),(0.00),(0.15,(0.15),(0.15,(0.15$,

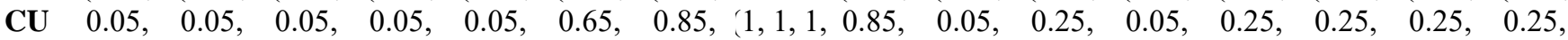

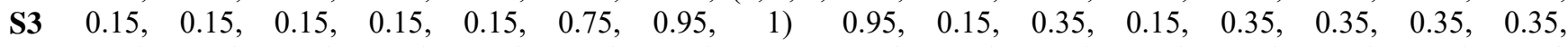
$\begin{array}{lllllllllllllll}0.25) & 0.25) & 0.25) & 0.25) & 0.25) & 0.85) & 1.00) & 1.00) & 0.25) & 0.45 & 0.25) & 0.45) & 0.45) & 0.45) & 0.45)\end{array}$

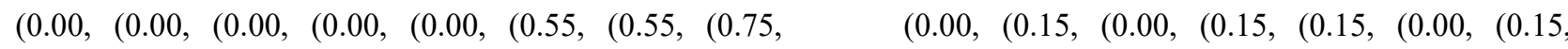

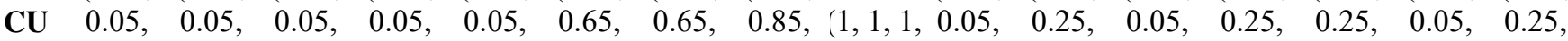

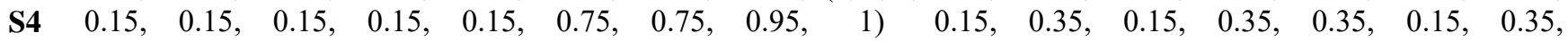
$\begin{array}{lllllllllllllll}0.25) & 0.25) & 0.25) & 0.25) & 0.25) & 0.85) & 0.85) & 1.00) & 0.25) & 0.45) & 0.25) & 0.45) & 0.45) & 0.25 & 0.45)\end{array}$

$(0.00,(0.00,(0.00,(0.00,(0.00,(0.00,(0.00),(0.00,(0.00, \quad 0.55,(0.75,(0.35,(0.35),(0.35,(0.35$,

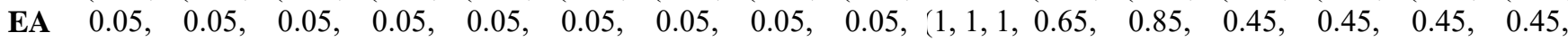

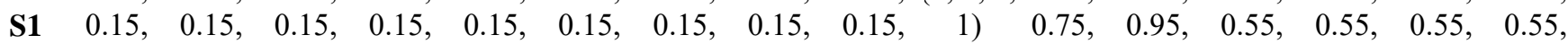
$\begin{array}{lllllllllllllll}0.25) & 0.25) & 0.25) & 0.25) & 0.25) & 0.25) & 0.25) & 0.25) & 0.25) & 0.85) & 1.00) & 0.65) & 0.65) & 0.65) & 0.65)\end{array}$

$(0.00,(0.00,(0.00,(0.00,(0.00,(0.00,(0.00),(0.15,(0.15,(0.55, \quad 0.75,(0.35),(0.35),(0.35,(0.35$, EA $\quad 0.05, \quad 0.05, \quad 0.05, \quad 0.05, \quad 0.05, \quad 0.05, \quad 0.05, \quad 0.25, \quad 0.25, \quad 0.65, \quad 1,1,1,0.85, \quad 0.45, \quad 0.45, \quad 0.45, \quad 0.45$,

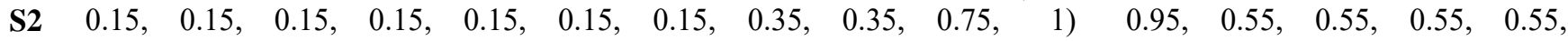

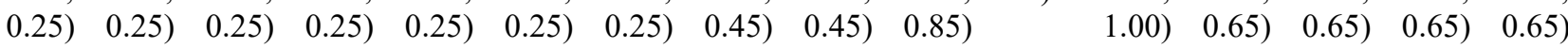

$(0.00,(0.00,(0.00,(0.00,(0.00,(0.00,(0.00),(0.00,(0.00,(0.75),(0.75, \quad 0.55,(0.35),(0.35,(0.55$,

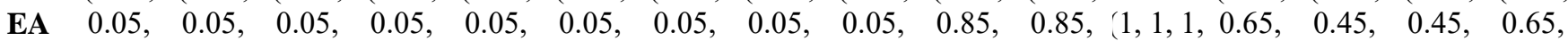

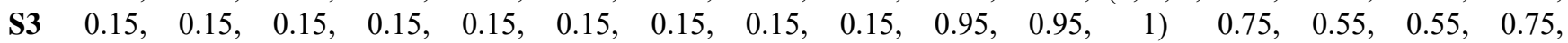
$\begin{array}{lllllllllllllll}0.25) & 0.25) & 0.25) & 0.25) & 0.25) & 0.25) & 0.25) & 0.25) & 0.25) & 1.00) & 1.00) & 0.85) & 0.65) & 0.65) & 0.85)\end{array}$

$(0.00,(0.00,(0.00,(0.00,(0.00,(0.00),(0.00),(0.15,(0.15,(0.35),(0.35,(0.55, \quad 0.75),(0.75,(0.55$,

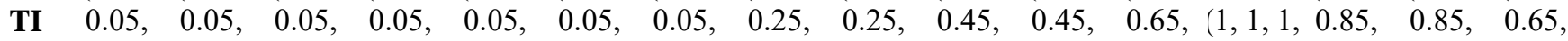

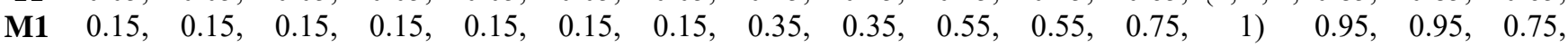
$\begin{array}{lllllllllllllll}0.25) & 0.25) & 0.25) & 0.25) & 0.25) & 0.25) & 0.25) & 0.45) & 0.45) & 0.65) & 0.65) & 0.85) & 1.00) & 1.00) & 0.85)\end{array}$

$(0.00,(0.00,(0.00),(0.00,(0.00,(0.00,(0.15),(0.15,(0.15,(0.35),(0.35),(0.35,(0.75, \quad) \quad(0.75,(0.55$,

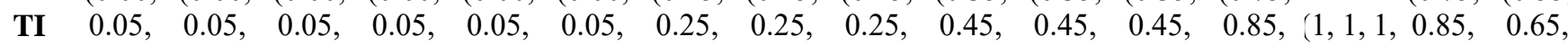

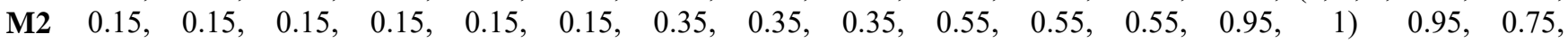
$\begin{array}{lllllllllllllll}0.25) & 0.25) & 0.25) & 0.25) & 0.25) & 0.25) & 0.45) & 0.45) & 0.45) & 0.65) & 0.65) & 0.65) & 1.00) & 1.00) & 0.85)\end{array}$

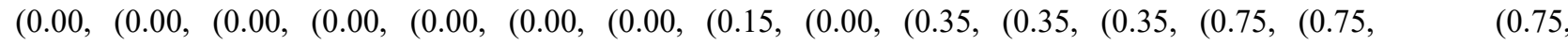

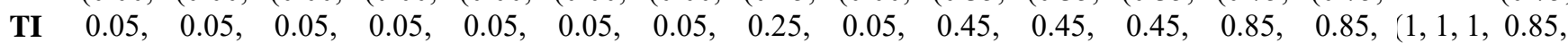

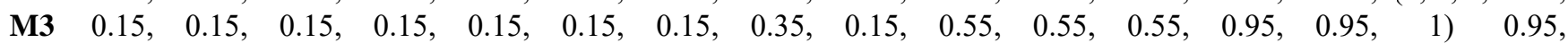
$\begin{array}{lllllllllllllll}0.25) & 0.25) & 0.25) & 0.25) & 0.25) & 0.25) & 0.25) & 0.45) & 0.25) & 0.65) & 0.65) & 0.65) & 1.00) & 1.00) & 1.00)\end{array}$ 
$(0.00, \quad(0.00, \quad(0.00, \quad(0.00, \quad(0.00, \quad(0.00, \quad(0.00, \quad 0.15, \quad 0.15, \quad 0.35, \quad(0.35, \quad(0.55, \quad(0.55, \quad(0.55, \quad(0.75$ TI $\quad 0.05, \quad 0.05, \quad 0.05, \quad 0.05, \quad 0.05, \quad 0.05, \quad 0.05, \quad 0.25, \quad 0.25, \quad 0.45, \quad 0.45, \quad 0.65, \quad 0.65, \quad 0.65, \quad 0.85, \quad(1,1,1$,

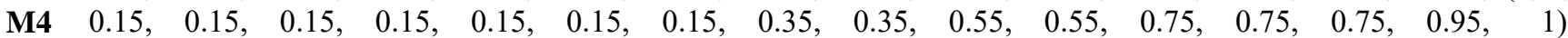

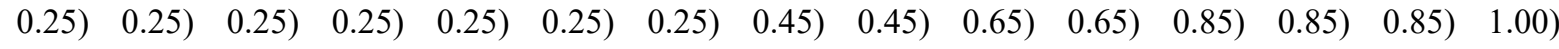

Table 13. CVs of Dependence and Driving power in FMICMAC

\begin{tabular}{ccccc}
\hline Factors & De (Fuzzy Value) & De $(\mathbf{C V})$ & Dr (Fuzzy Value) & Dr (CV) \\
\hline REP1 & $(3,3.95,5.45,6.95)$ & 4.76 & $(3.8,4.95,6.45,7.95)$ & 5.74 \\
REP2 & $(3,3.95,5.45,6.95)$ & 4.76 & $(3.8,4.95,6.45,7.95)$ & 5.74 \\
REP3 & $(3.2,4.15,5.65,7.15)$ & 4.96 & $(4.2,5.35,6.85,8.35)$ & 6.14 \\
REP4 & $(3.2,4.15,5.65,7.15)$ & 4.96 & $(4.4,5.55,7.05,8.55)$ & 6.34 \\
REP5 & $(2.8,3.75,5.25,6.75)$ & 4.56 & $(4.2,5.35,6.85,8.35)$ & 6.14 \\
CUS1 & $(4.2,5.35,6.85,8.35)$ & 6.14 & $(2.65,3.55,5.05,6.55)$ & 4.37 \\
CUS2 & $(3.95,5.15,6.65,8.1)$ & 5.93 & $(3,3.95,5.45,6.9)$ & 4.76 \\
CUS3 & $(4.95,6.35,7.85,9.25)$ & 7.10 & $(3.8,4.95,6.45,7.85)$ & 5.73 \\
CUS4 & $(5,6.35,7.85,9.3)$ & 7.11 & $(3.45,4.55,6.05,7.5)$ & 5.34 \\
EAS1 & $(3.7,4.75,6.25,7.7)$ & 5.54 & $(3.7,4.75,6.25,7.7)$ & 5.54 \\
EAS2 & $(4,5.15,6.65,8.1)$ & 5.93 & $(4,5.15,6.65,8.1)$ & 5.93 \\
EAS3 & $(4.3,5.35,6.85,8.25)$ & 6.14 & $(4.3,5.35,6.85,8.25)$ & 6.14 \\
TIM1 & $(4.6,5.75,7.25,8.65)$ & 6.53 & $(4.6,5.75,7.25,8.65)$ & 6.53 \\
TIM2 & $(4.55,5.75,7.25,8.65)$ & 6.52 & $(4.55,5.75,7.25,8.65)$ & 6.52 \\
TIM3 & $(4.45,5.55,7.05,8.4)$ & 6.33 & $(4.45,5.55,7.05,8.4)$ & 6.33 \\
TIM4 & $(4.4,5.55,7.05,8.5)$ & 6.33 & $(4.4,5.55,7.05,8.5)$ & 6.33 \\
\hline
\end{tabular}

According to Figure 4, there are no factors that Cluster I Autonomous factors. It can be seen the signs for the existences of the relationships between the considered 16 factors in this FMICMAC method.

Meanwhile, the greatest number of factors have focused on Cluster III - Linkage with seven factors. Cluster III - Linking factors is an important link to form supporting factors in Cluster II, extremely important to build a strong relationship including EAS2, EAS3, TIM1, TIM2, TIM3, TIM4, CUS3. The factors in this Cluster III are not only affected specifically by Cluster IV's factors but also have a certain influence on
Cluster II's factors. It can be interpreted that when the Cluster IV's values change that will cause the value changes in this Cluster III. WITHOUT STOPPING, the Cluster II's factors will also be changed. This can also be seen as a Cluster that contained the intermediate factors affecting the LEs' competitiveness.

In Cluster II, there are three factors including CUS1, CUS2 and CUS4. These are factors which are determined under highly dependent power. Therefore, the factors in this Cluster II will not play an important role which has impacted the LEs' competitiveness. 


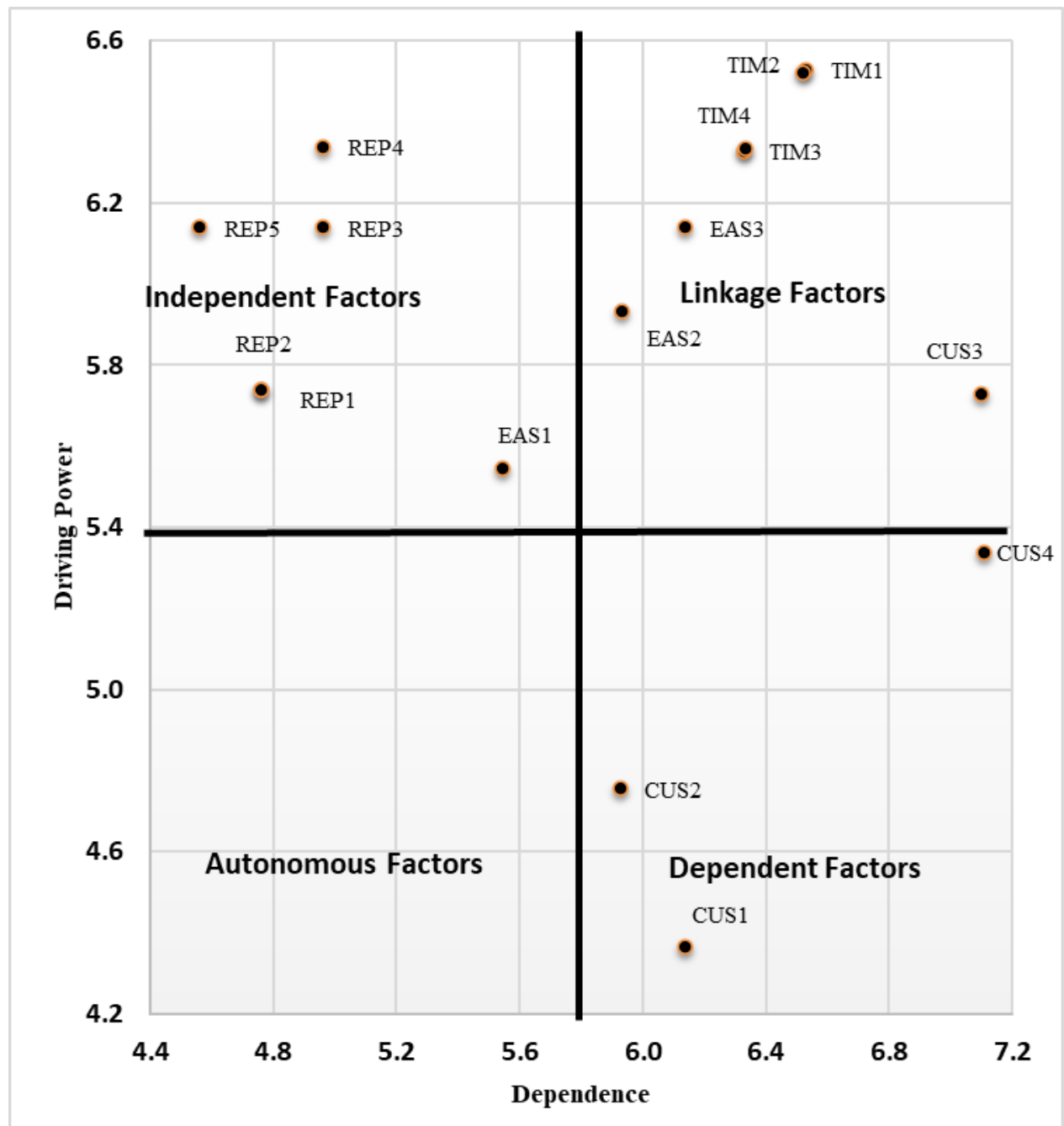

Figure 4. FMICMAC analysis

In contrast, with simultaneous characteristics strong Dr and weak De, Cluster IV - Independence has played very important roles which significantly impact on not only the Cluster II's factors but also the LEs' competitiveness. REP4, REP 5, REP3, REP1, REP2, EAS1 are factors belonging in this Cluster IV. Especially, there are five out of six factors contributing to the Reputation characteristic which has helped LEs' managers reach a better insight into Reputation before they think about the larger goals when considering factors affecting their own enterprises' competitiveness.

This study is inherited from many variables that support the orientation of effective competitiveness for enterprises operating in the field of logistics.

Case study of LEs in the MD, Vietnam, a practical description of using the integrated IDS-FISM-FMICMAC methodology to model and identify significant factors role in determining the competitiveness of LEs in this region. This integrated approach will help managers control the factors that enhance LEs' competitiveness better than ever before.

\section{CONCLUSION}

Study on the LEs, specifically in the logistics service industry, is one of the research topics that attracts the attention of many authors. However, there have not been many studies on this topic in Vietnam, due to the peculiarities and differences of the logistics service industry compared to other normal services. The overall goal of this study paper is to determine several factors affecting competitiveness as well as assess the influence of these elements on the competitiveness of logistics enterprises in the MD. Based on theory and formal research model, research seven factors including CUS, REP, INF, QLS, EAS, TRA, and TIM with 29 observed variables used to measure the concept of competitiveness and factors affecting the LEs' competitiveness. The results of data analysis and testing indicate that the model is coherent with the data gathered. The three removed elements include infrastructure, tracking and tracing, and quality of logistics service. The remaining four factors are accepted including: CUS, EAS, TIM and REP with the corresponding regression coefficient of $0.539 ; 0.395 ; 0.260 ; 0.151$. Four hypotheses are accepted including H1 (REP), H2 (CUS), H4 (EAS), H7 (TIM). Three hypotheses are rejected consisting of H3 (INF), H5 (QLS) and H6 (TRA) with high levels 5\% significance and $95 \%$ reliability. All the four valid factors have a positive effect, in the same direction, on the competitiveness of enterprises in the MD. In which, the factor Customs has the largest effect with the regression coefficient 0.539 .

The results of this paper create a highly academical basis for LEs' managers to understand the possibility of developing their own enterprises' competitiveness in in the MD market. In addition, understanding the key characteristics of the 
competitiveness will their reactions faster whenever the market changes.

Limitations and scope for future work

In this paper, although the subjectivity in the process of determining factors has been overcome with the improved descriptive statistics method combined with the process of reviewing reputable journals; industry experts of logistics industry and real practitioners, the nature of this study is partly subjective judgements. Besides, there has not been currently much comparable research on this topic in the MD so we do not have many sources of reference to make studies come to be the greater goal. The future study should be extended to use lots of methodologies and approaches to determine most significant factors in different industries, in other regions in Vietnam.

\section{ACKNOWLEDGEMENT}

This work is partly supported by the research project No. DHFPT/2021/11 granted by FPT University.

Graduate student Nguyen Thang Loi was funded by Vingroup Joint Stock Company and supported by the Domestic Master/ $\mathrm{PhD}$ Scholarship Programme of Vingroup Innovation Foundation (VINIF), Vingroup Big Data Institute (VINBIGDATA), code VINIF.2020.TS.26

\section{REFERENCES}

[1]. Vietnam Chamber of Commerce and Industry (VCCI) (2020), "Mekong Delta Annual Economic Report 2020: Enhancing competitiveness for sustainable development". [pdf] Can Tho city: Can Tho University Publisher. Pp.257. (in Vietnamese). Available at: //fsppm.fulbright.edu.vn/ [Accessed 7 Jul. 2021].

[2]. Ty, H., "Developing logistics services to increase competition for agricultural and aquatic products in the Mekong Delta", [Online] Can Tho Trade and Investment Promotion Center and Exhibition", (in Vietnamese). Available at: https://canthopromotion.vn/phat-trien-dich-vu-logistics-tangcanh-tranh-cho-nong-thuy-san-dbscl/ [Accessed $10 \mathrm{Jul}$. 2021].

[3]. Ministry of Industry and Trade of Vietnam, "Vietnam Logistics report 2021: Cut off logistics costs". [pdf] Ha Noi: Industry and trade publisher. (in Vietnamese). Available at: //gosmartlog.com/ [Accessed 8 Jul. 2021].

[4]. Binh, N. T \& Huong, T. T. T., "Impact of Decisions in Freight Transport Management on Rice Logistics in the Mekong Delta of Vietnam", Transportation Research Procedia, Vol. 48, pp. 540-554, 2020.

[5]. Le, T. \& Le, N., "Analysis of factors affecting decisions to outsource logistics services of seafood exporters in the mekong delta", The Scientific Journal of Tra Vinh University, Vol. 1, No. 41, pp. 1-9, 2020.

[6]. Worldbank.org, (2018). LPI Home. [online] Available at: https://lpi.worldbank.org/ [Accessed 13 July 2021].

[7]. Hanh, V.T.K., "Discussing Competitiveness of the Vietnam Logistics Industry", Journal of Asian Development, Vol. 6, No. 2, pp. 1-22, 2020.

[8]. Mohammad M. Hamed., "Logistics Performance and Freight Sector in Jordan", European Journal of Scientific Research, Vol. 152, No. 4, pp. 516-527, 2019.

[9]. Limcharoen, A., Jangkrajarng, V., Wisittipanich, W., Ramingwong, S., "Thailand Logistics Trend: Logistics
Performance Index", International Journal of Applied Engineering Research, Vol. 12, No. 15, pp. 4882-4885, 2017

[10]. Çemberci, M., Civelek, M. E., \& Canbolat, N., "The moderator effect of global competitiveness index on dimensions of logistics performance index.", Procedia-social and behavioral sciences 195: 1514-1524, 2015

[11]. Tian, Y., Lai, F., \& Daniel, F., "An examination of the nature of trust in logistics outsourcing relationships", Industrial Management \& Data Systems, Vol.108, No.3, pp. 346-367, 2008

[12]. Eidat, Y., Kelly, A.,Roche, F., Eyadat, F., "Green and Competitive? An empirical test of the mediating role of environmental innovation strategy", Journal of World Business, 43, 133, 2008

[13]. Savitha M T and Dr. Mary George, "New Methods for Ranking of TFNs", Advances in Fuzzy Mathematics. Volume 12, Number 5, pp. 1159-1170, 2017.

[14]. Dube A \& Gawande R, "ISM-fuzzy MICMAC approach for analysis of GSCM enablers", Int J Logist Syst Manag, 24(4), pp. 426-451, 2016a.

[15]. Sher, Peter \& Yang, Phil, "The Effects of Innovative Capabilities and R\&D Clustering on Firm Performance", Technovation. 25. 33-43, 2005.

[16]. Tabachnick, B. G., \& Fidell, L. S., "Using multivariate statistics (3rd ed.)", New York: Harper Collins, 1996.

[17]. Nguyen Thang Loi, H.T.T Hoa, P.D.T.Anh, N.D.Khoi, N.T.K.My, N.T.Luan, " The Integration of Fuzzy-ISM, FuzzyAHP, and Fuzzy-MICMAC Approach under Trapezoid Fuzzy Linguistic to Analyze Enablers of The Logistics Outsourcing Relationship: Mekong Delta, Vietnam Rice Supply Chain Context", International journal of circuits, systems and signal processing, 15, 1260-1281, 2021.

[18]. Yadav, S. \& Singh, S.P., "Blockchain critical success factors for sustainable supply chain", Resources, Conservation and Recycling, Vol. 152, 104505, 2020.

[19]. L. A. Zadeh, "Fuzzy sets", Information and control, vol. 8, pp. 338-353, 1965.

[20]. Abdullah Al Gizi, "MPPT Of Solar Energy Converter With High-Sensitive Fuzzy PID Controller", WSEAS Transactions on Computers, vol. 20, pp. 17-29, 2021.

[21]. Constantin Voloşencu, "Study of the Angular Positioning of a Rotating Object with Fuzzy Control by State Feedback", WSEAS Transactions on Computers, vol. 20, pp. 282-288, 2021a.

[22]. Constantin Voloşencu, "Angular Positioning Based on State Feedback Fuzzy Control", WSEAS Transactions on Computers, vol. 20, pp. 268-273, 2021b.

[23]. Mann, Prem S., "Introductory Statistics (2nd ed.)". Wiley. ISBN 0-471-31009-3, 1995.

[24]. Andrew N. Christopher, "Drawing Conclusions From Data: Descriptive Statistics, Inferential Statistics, and Hypothesis Testing", Interpreting and Using Statistics in Psychological Research, 2455 Teller Road, Thousand Oaks California 91320: SAGE Publications, Inc, pp. 145-183, 2017.

[25]. Nunnally J.C. (1978) "An Overview of Psychological Measurement .In: Wolman B.B. (eds) Clinical Diagnosis of Mental Disorders". Springer, Boston, MA, 1978.

[26]. J. N. Warfield, "Toward Interpretation of Complex Structural Models," in IEEE Transactions on Systems, Man, and Cybernetics, vol. SMC-4, no. 5, pp. 405-417, Sept. 1974.

[27]. Ghosh, A., \& J. Fedorowicz. "The Role of Trust in Supply Chain Governance." Business Process Management Journal, 14 (4): 453-470, 2008.

\section{Creative Commons Attribution License 4.0 (Attribution 4.0 International, CC BY 4.0)}

This article is published under the terms of the Creative Commons Attribution License 4.0

https://creativecommons.org/licenses/by/4.0/deed.en_US 